Revista IBERC

v. 3, n. 2, p. 241-267, maio/ago. 2020

www.responsabilidadecivil.org/revista-iberc

DOI: https://doi.org/10.37963/iberc.v3i2.130

\title{
MEDICAÇÃO APLICÁVEL À COVID-19, CONSENTIMENTO DO PACIENTE E RESPONSABILIDADE CIVIL DO MÉDICO
}

\author{
MEDICATION APPLICABLE TO COVID-19, PATIENT'S CONSENT AND CIVIL \\ LIABILITY OF THE MEDICAL DOCTOR
}

RESUMO: $O$ artigo tem por finalidade, a partir da falta de evidência científica no emprego da Cloroquina e da Hidroxicloroquina no tratamento da Covid-19, em nível mundial, discutir se eles devem ou não ser empregados nesses casos. $O$ que se sabe é que o uso desses fármacos pode acarretar uma série de efeitos colaterais aos pacientes. Deve o médico, portanto, obter o consentimento informado e esclarecido do paciente. Para isso, o doente deverá ser informado de todos os riscos aos quais ele estará sujeito, se consentir na aplicação da medicação. O exercício da autonomia do paciente bem informado é essencial, para que o médico não venha a ser responsabilizado por algum mal que possa

\begin{abstract}
The article aims, based on the lack of scientific evidence on the use of Chloroquine and Hydroxychloroquine in the treatment of Covid-19, worldwide, to discuss whether or not they should be used in these cases. What is known is that the use of these drugs might cause a series of side effects for patients. The physician must, therefore, obtain the patient's informed and clarified consent. For this, the patient should be informed of all risks to which he/she will be subject, if he/she consents to the application of the medication. The exercise of autonomy of the well-informed patient is essential, so that the medical doctor shall not be held responsible for any harm that may affect the patient, especially due to the lack of information. It
\end{abstract}

' Doutora e mestre em Direito Civil pela Pontifícia Universidade Católica de São Paulo, Pós Graduada em Direito Processual Civil pela PUC/SP. Atualmente é professora em tempo integral na Universidade São Judas Tadeu (USJT). Professora de direito civil da Universidade Mogi das Cruzes - campus Villa Lobos. Professora de direito civil na Universidade São Judas Tadeu - São Paulo. Professora convidada da PósGraduação lato sensu da PUC/SP (COGEAE) curso Direito Contratual. Ex-professora orientadora de processo civil do Curso Pós-Graduação lato sensu da Uniderp-LFG. Participa como membro efetivo da Comissão de Ensino Jurídico da OAB/SP. Realiza atividades de extensão e pesquisa na USJT. Atua como professora nos Cursos de Oficina de Contratos e Direito Imobiliário na Escola Superior de Advocacia de São Paulo e Escola Paulista de Direito em São Paulo. Experiência profissional de mais de 23 anos na área de consultoria jurídica, contencioso cível e recuperação de crédito. Nos últimos 25 anos obteve sólida atuação em discutir, analisar e solucionar questões relacionadas a processo civil, contratos e empreendimentos imobiliários. Interesse de Pesquisa: Direitos Reais, Registral e Sucessão. ORCID: https://orcid.org/0000-0001-5601-7037

ii Pós-doutora pelo Max-Planck-Institut für ausländisches und internationales Privarecht, em Hamburgo/Alemanha, com bolsa da Alexander von Humboldt-Stiftung. Doutora em Direito pela Universität Bremen/Alemanha (1995), Mestre em Direito pela Westfälische Wilhems-Universität Münster/Alemanha (1992) e Mestre em Direito pela Universidade de São Paulo (1989). Bacharel em Direito pela Faculdade de Direito da Universidade de São Paulo (1982). Professora Titular da Faculdade de Direito da Universidade São Judas Tadeu. Ex-Professora Titular e Pesquisadora do Programa de Mestrado em Direito do Centro Universitário Fieo - UNIFIEO; Assessora ad hoc da FAPESP. Tem experiência na área do Direito Civil, Direito do Consumidor, Direitos Fundamentais e Bioética. Finalista do Prêmio Jabuti de 2013 (Bioética e Direitos Fundamentais). Coordenadora do Núcleo de Biodireito e Bioética da ESA-OAB/SP. Professora Colaboradora do Mestrado em Ciência do Envelhecimento da Universidade São Judas Tadeu. ORCID: https://orcid.org/0000-0003-4270-5976 
acometer o doente, especialmente por falta de informação. Chegou-se à conclusão de que o médico não poderá ser responsabilizado por eventuais danos à saúde do paciente, se ele tiver sido informado de modo claro e compreensível sobre o uso da Cloroquina ou da Hidroxicloroquina.

Palavras-chave: Covid-19; autonomia existencial; consentimento informado; cloroquina; responsabilidade civil do médico. has been concluded that the doctor cannot be held responsible for any damage to the patient's health, if he/she has been informed in a clear and understandable way about the use of Chloroquine or Hydroxychloroquine.

Keywords: Covid-19; existential autonomy; informed consent; chloroquine; medical doctor's civil liability.

SUMÁRIO: 1. Introdução. 2. Sobre o uso da Cloroquina e os Protocolos/Recomendações dos Órgãos Legais de Medicina. 3. Do paternalismo hipocrático à autonomia existencial do paciente. 4. Consentimento informado e esclarecido, transparência e poder de decisão do paciente. 5. Sobre a (não) responsabilização civil do médico no uso da Cloroquina e da Hidroxocloroquina. 6. Conclusão. Referências.

\section{INTRODUÇÃO}

Desde o final de 2019 o mundo vem enfrentando o vírus Sars-Cov-2, da família do Coronavírus, que causa a chamada Covid-19, que pode, em alguns casos, levar a óbito a pessoa que o contrai. Ele surge na China e dissemina-se rapidamente pelos continentes, o que fez com que a Organização Mundial da Saúde - OMS -, declarasse, em março de 2020, situação de pandemia, face ao grande número de doentes e mortes até aquele momento já existentes. No Brasil o primeiro caso foi diagnosticado em fevereiro de 2020 na cidade de São Paulo. Fato é que, somando-se o número de mortos nos mais diversos países em decorrência da Covid-19, já se chegou à casa dos milhares. E tudo isso na chamada "primeira onda" do vírus. Pesquisas e evidências científicas são aguardadas e, sem que se tenha medicação capaz de controlar ou debelar de forma efetiva o vírus, - que é contraído facilmente por todas as faixas etárias - a mortalidade só aumenta, sendo as pessoas acima dos sessenta (60) anos e/ou com comorbidades, as mais atingidas.

O problema central que a sociedade global enfrenta atualmente é como combater o vírus, uma vez que não há medicação que tenha demonstrado ser totalmente eficaz no seu combate. No Brasil, apesar da falta de evidência científica, o governo federal determinou o uso de dois medicamentos, a saber: a Cloroquina e a Hidroxicloroquina. Estes dois fármacos, no entanto, normalmente prescritos para tratar outras comorbidades, tem tido seu emprego bastante questionado em razão dos efeitos colaterais que causam, não sendo possível descartar-se, inclusive, a morte do paciente.

Assim, a partir do momento em que o governo estabelece que o médico deve utilizar uma medicação, cuja eficácia, ressalte-se, ainda não está comprovada, o consentimento do paciente torna-se imprescindível. Afinal, é da sua vida que se trata. Por isso, sua autonomia existencial, isto é, aquela que tem a ver com as questões relativas à sua pessoa, por conseguinte, à sua saúde, tem de ser-lhe apresentadas de forma tal, que ele possa compreender a extensão do benefício ou do malefício que a medicação poderá lhe causar. 
O presente artigo tratará dos temas acima referidos. Primeiramente, apresenta-se a problemática do uso da Cloroquina e da Hidroxicloroquina. A seguir, analisa-se a participação ativa do paciente, por meio do consentimento informado e esclarecido na relação médicopaciente. Por fim, examina-se a responsabilidade do profissional da saúde ao empregar medicação que não apresenta, até o momento, evidência científica comprovada, de que poderá resultar em benefício para o paciente.

\section{SOBRE O USO DA CLOROQUINA E OS PROTOCOLOS/RECOMENDAÇÕES DOS ÓRGÃOS LEGAIS DE MEDICINA}

Protocolos Médicos são documentos expedidos pelos órgãos oficiais da saúde que, em linhas gerais, informam critérios para o diagnóstico de uma doença como também os medicamentos apropriados, mecanismos de controle clínico e o acompanhamento dos resultados terapêuticos a serem seguidos pelos profissionais da área da saúde. ${ }^{1}$ Eles são emitidos com base em evidência científica e, por isso, devem ser sustentados em critérios de "eficácia, segurança, efetividade e custo-efetividade das tecnologias recomendadas". 2

Para combater as moléstias, todo novo medicamento deverá ser registrado no Ministério da Saúde ${ }^{3}$, cumprindo à Agência Nacional de Vigilância Sanitária (Anvisa) ${ }^{4}$ assegurar a pureza, eficácia e a regularidade da atividade produtiva. $^{5}$

Cada medicamento é registrado para determinados tratamentos e deve ser usado com parâmetros específicos de acordo com estudos que foram feitos e exigidos - pela Anvisa - para seu registro. A real preocupação é com a saúde pública, mas, também, de impedir a proliferação de promessas milagrosas ou algo mais grave como medicamentos que podem gerar danos à saúde.

Quando o medicamento é usado conforme seu registro, ou seja, o fármaco foi homologado pela Anvisa, tendo sido destinado para um determinado tipo de doença, diz-se que

\footnotetext{
1 MINISTÉRIO DA SAÚDE. Protocolos Clínicos e Diretrizes Terapêuticas - PCDT. Disponível em: http://saude.gov.br/protocolos-e-diretrizes. Acesso em: 4 jul. 2020.

2 MINISTÉRIO DA SAÚDE. Protocolos Clínicos e Diretrizes Terapêuticas - PCDT. Disponível em: http://saude.gov.br/protocolos-e-diretrizes. Acesso em: 4 jul. 2020.

${ }^{3}$ V. Lei n. 6.360/1976, art. 12 - Nenhum dos produtos de que trata esta Lei, inclusive os importados, poderá ser industrializado, exposto à venda ou entregue ao consumo antes de registrado no Ministério da Saúde. Disponível em: http://www.planalto.gov.br/ccivil_03/leis/l6360.htmç. Acesso em: 26 Jun. 2020.

${ }^{4}$ A Anvisa - Agência Nacional de Vigilância Sanitária -, criada pela Lei n. 9.782/1999, é o órgão responsável, de acordo com 0 art. $6^{\circ}$ do citado diploma legal, para "promover a proteção da saúde da população, por intermédio do controle sanitário da produção e da comercialização de produtos e serviços submetidos à vigilância sanitária, inclusive dos ambientes, dos processos, dos insumos e das tecnologias a eles relacionados, bem como o controle de portos, aeroportos e de fronteiras. Disponível em: http://www.planalto.gov.br/ccivil_03/leis/L9782.htm. Acesso em: 26 jun. 2020.

${ }^{5} \mathrm{O}$ art. $1^{\circ}$ da Lei n. 6.360/1976, disciplina: "Ficam sujeitos às normas de vigilância sanitária instituídas por esta Lei os medicamentos, as drogas, os insumos farmacêuticos e correlatos, definidos na Lei $n^{\circ} 5.991$, de 17 de dezembro de 1973, bem como os produtos de higiene, os cosméticos, perfumes, saneantes dos domissanitários, produtos destinados à correção estética e outros adiante definidos." Disponível em: http://www.planalto.gov.br/ccivil_03/leis/l6360.htm. Acesso em: 26 jun. 2020.
} 
o uso é on label; e, tudo o que destoa desse uso, na forma dos estudos que embasaram o registro do medicamento, é off label ${ }^{6}$. Ou seja: o uso é experimental ${ }^{7}$.

Note-se que, para o tratamento da Covid-19 não há, ainda, nenhuma droga específica. Faz-se possível, portanto, a prescrição de medicamentos off label. Cuida-se aqui de fármacos já existentes, com registro no Ministério da Saúde, chancelados pela Anvisa ${ }^{8}$, e que têm outras indicações de uso ${ }^{9}$. Empregá-los, entretanto, para o tratamento de outras moléstias, não é considerado ilegal ${ }^{10}$. Adverte-se, contudo, de advertir para o fato de que o fármaco pode tanto trazer benefícios como produzir efeitos adversos, prejudicando o paciente ${ }^{11}$.

No fundo, a verdade é que a administração de medicamento com indicação terapêutica distinta daquela para a qual fora aprovado é comum na medicina. Isto é o que está acontecendo atualmente no caso da Covid-19, causada pelo Coronavírus Sars-Cov 2. Dois medicamentos com caráter off label, a cloroquina e a hidroxicloroquina, que foram aprovados inicialmente para o tratamento da malária, lúpus e artrite reumatoide, têm sido indicados para seu tratamento. ${ }^{12}$ Interessante notar, porém, que na bula dessas medicações consta que o seu emprego para a Covid-19 é considerado off label. Além disso, até o momento, pesquisas demonstram que graves são os efeitos adversos que o seu uso pode causar, tais como distúrbios cardíacos, oculares, hepáticos, psiquiátricos, sistema linfático, dentre outros ${ }^{13}$.

6 Disponível em: https://politica.estadao.com.br/blogs/fausto-macedo/o-uso-off-label-da-cloroquina-dahidroxicloroquina-e-da-dexametasona-para-o-tratamento-da-covid-19/. Acesso em: 24 Jun. 2020. A esse respeito, ademais, v.: DADALTO, Luciana; SOARES, Flaviana Rampazzo. Responsabilidade médica e prescrição off-label de medicamentos no tratamento da Covid-19. Revista IBERC, Belo Horizonte, v. 3, n. 2, Ahead of Print, maio./ago. 2020. Disponível em: https://doi.org/10.37963/iberc.v3i2.112. Acesso em: 27 jun. 2020.

7 "Médico pode tratar pacientes que tenham uma certa condição que, por analogia, ou por base fisiopatológica, ele acredite possam vir a se beneficiar de um determinado medicamento não aprovado para aquela patologia, mas aprovado o medicamento pela Anvisa. Quando o medicamento é empregado nas situações descritas acima está caracterizado o uso off label do medicamento, ou seja, o uso não foi aprovado para os fins específicos daquela doença e que não consta da bula. O uso off label de um medicamento é feito por conta e risco do médico que o prescreve". Disponível em: https://bit.ly/3gLcGap. Acesso em: 18 Jun. 2020.

${ }^{8}$ Arts. $2^{\circ}$ e $3^{\circ}$ da Lei n. 9.782/1999.

${ }^{9}$ FERREIRA, Lilian de Abreu, et al. A alta prevalência de prescrições de medicamentos off-label e não licenciados em unidade de terapia intensiva pediátrica brasileira. Revista da Associação Médica Brasileira. São Paulo, v. 58, n. 1, p. 82-87, 2012.

10 NOGUEIRA, Roberto Henrique Porto. Responsabilidade Civil do Médico na Prescrição off label de medicamentos para Covid-19. Webinar Especial do IBERC: Coronavírus e Responsabilidade Civil. Disponível em: https://www.youtube.com/watch?v=TWAj8TZn8t0\&t=17202s. Acesso em: 21 Abr. 2020. V. ainda sobre o tema: Enunciado $\mathrm{n}^{\circ} 15$ da I Jornada de Direito da Saúde: "As prescrições médicas devem consignar o tratamento necessário ou o medicamento indicado, contendo a sua Denominação Comum Brasileira (DCB) ou, na sua falta, a Denominação Comum Internacional (DCl), o seu princípio ativo, seguido, quando pertinente, do nome de referência da substância, posologia, modo de administração e período de tempo do tratamento e, em caso de prescrição diversa daquela expressamente informada por seu fabricante, a justificativa técnica." Disponível em: http://ejef.tjmg.jus.br/enunciados-das-jornadas-dodireito-da-saude-do-cnj/. Acesso em: 01 Jul. 2020.

11 DADALTO, Luciana; SOARES, Flaviana Rampazzo. Responsabilidade médica e prescrição off-label de medicamentos no tratamento da Covid-19. Revista IBERC, Belo Horizonte, v. 3, n. 2, Ahead of Print, maio./ago. 2020. Disponível em: https://doi.org/10.37963/iberc.v3i2.112. Acesso em: 27 jun. 2020.

12 Sobre o uso dessas medicações v. Portal da Fiocruz. Disponível em: https://portal.fiocruz.br/ sites/portal.fiocruz.br/files/documentos/orientacoes_sobre_a_cloroquina_nota_tecnica_.pdf. Acesso em: 1 ago. 2020.

13 RAPOSO, Vera Lúcia. Da proteção dos consumidores-pacientes na prescrição off-label. Revista de Direito do Consumidor. São Paulo: Revista dos Tribunais, v. 110, p. 163-186, 2017. 
Parece ser indubitável que a pandemia gere a cada dia uma expectativa de soluções imediatas para o tratamento da Covid-19, sendo lançadas, concomitantemente, diversas informações distorcidas sobre as evidências científicas de tratamento, o que acaba por gerar maior ansiedade na população ${ }^{14}$. Diante desse cenário, como tomar a decisão correta no uso desses medicamentos? Em quais hipóteses, e de que forma, prescrevê-los com a devida segurança jurídica? Como selecionar as terapias alternativas minimamente adequadas para Covid-19 em termos de eficácia e segurança?

No anseio de encontrar as respostas para as perguntas levantadas, necessárias algumas reflexões sobre o papel das chamadas evidências científicas ${ }^{15}$.

A palavra evidência costuma ser empregada no sentido de "caráter do que é evidente, manifesto, do que não deixa dúvidas; prova"16. Para a filosofia, "o conceito de evidência tem um papel central na compreensão do conhecimento e da racionalidade; somente se tem conhecimento quando existe um convencimento verdadeiro baseado em uma evidência forte"17.

Para Martha Silvia Martínez-Silveira ${ }^{18}$ :

Uma evidência científica é entendida como o conhecimento explícito, sistemático, que utiliza métodos transparentes, que precisa de confirmação, e para que isso ocorra, a experimentação passa a ser um dos caminhos. As características da evidência na área médica são a provisoriedade, revogabilidade, incompletude, ser emergente, ser limitada, coletiva e assimétrica. As duas primeiras características dão uma clara ideia de que raramente uma evidência médica trará certeza absoluta, e poderá sempre ser revista à luz de novas evidências.

Para a autora, "uma mesma evidência pode ser categorizada com diferentes níveis e força segundo o sistema utilizado". A chamada Pirâmide da Evidência sintetiza como avaliar a qualidade da evidência e pode ser visualizada segundo a figura abaixo ${ }^{19}$ :

14 “(...) existe uma divisão da prescrição off-label na medida em que podemos ter uma recomendação de
um medicamento para uma doença com sintomas completamente diferentes daquela para a qual o usos e
encontra aprovado, ou, por outro lado, a prescrição de um medicamento para tratar uma doença ou
condição para a qual tenha sido aprovado, mas alterando algumas especificações. (...) No entanto, em
termos práticos, não existe um estudo comprovado que possa assegurar que um dos casos seja mais
seguro que outro". BARBOSA, Carla; MATOS, Mafalda Francisco. Prescrição off-label, direito à informação,
consentimento informado e processo clínico eletrônico no direito português. Cadernos Ibero-Americanos de
Direito Sanitário. Brasília, v. 5 , n. 3, p. $157-179,2016$, p.163.
${ }^{15}$ A evidência científica é aquela utilizada para servir de base para confirmação ou negação de teoria ou
hipótese científica. Para que a evidência seja considerada científica é necessário que haja pesquisa
realizada dentro de preceitos científicos, que seus resultados tenham sido publicados e, assim, passível de
replicação em outros locais.
Disponível em: http://www.anm.org.br/arquivos/2483826/Maur\%C3\%ADcio\%20Gomes\%20Pereira\%20-
\%20Mem\%C3\%B3ria.pdf.. Acesso em: 19 jun. 2020 .
16 Disponível em: https://www.dicio.com.br/pesquisa.php?q=evidencia. Acesso em: 30 jun. 2020 .
17 MARTíNEZ-SILVEIRA. Martha Silvia. Revisões sistemáticas como fonte de evidências científicas em
Saúde. 2015. 185f. Tese (Doutorado) - Instituto de Comunicação e Informação Científica e Tecnológica em
Saúde. Pós-Graduação em Informação e Comunicação em Saúde, Rio de Janeiro, 2015 .
18 MARTíNEZ-SILVEIRA. Martha Silvia. Revisões sistemáticas como fonte de evidências científicas em
Saúde. 2015. 185f. Tese (Doutorado) - Instituto de Comunicação e Informação Científica e Tecnológica em
Saúde. Pós-Graduação em Informação e Comunicação em Saúde, Rio de Janeiro, 2015 .
19 MARTíNEZ-SILVEIRA. Martha Silvia. Revisões sistemáticas como fonte de evidências científicas em
Saúde. 2015. 185f. Tese (Doutorado) - Instituto de Comunicação e Informação Científica e Tecnológica em 


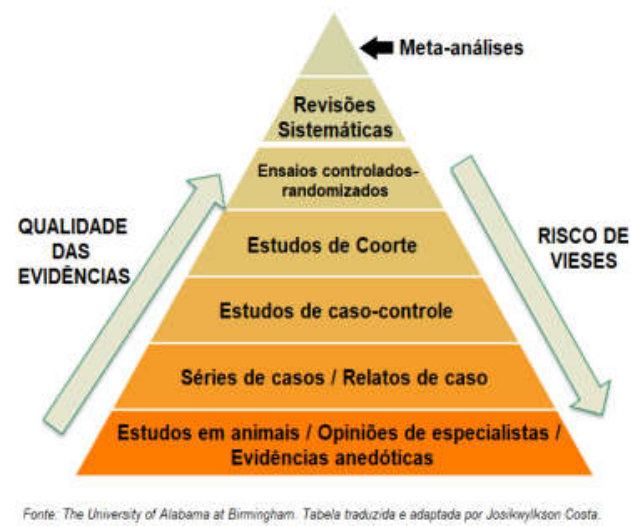

Ela explica, ademais, que esta pirâmide da evidência "foi criada para estabelecer a hierarquia dos diferentes níveis de evidência científica de acordo com os tipos de desenhos de estudos e com base no impacto de cada um". ${ }^{20}$ Esclarece ainda que "cada nível de baixo para cima representa um tipo de estudo com maior rigor, qualidade e confiabilidade em relação ao nível inferior". Desta forma, os resultados dos estudos que estiverem "mais acima da pirâmide são considerados mais acurados, com menor chances estatísticas de erro e com menor viés ${ }^{21}$ nas variáveis que podem influenciar o resultado"22.

Percebe-se que as evidências científicas seguras são aquelas obtidas por meio de experimentos desenhados a partir de métodos específicos, e que servem para assegurar a possibilidade da projeção do achado para outros contextos, podendo, assim, ser repetidos com provável êxito ${ }^{23}$. Enfim, quanto maior o controle de erros em determinado estudo, maior o nível de qualidade da evidência. Em outras palavras, dependerá da quantidade de pessoas estudadas, do tempo de acompanhamento, do estudo ser metodologicamente bem estruturado, ser randomizado e cego ${ }^{24}$, para que se tenha evidências mais seguras.

$\mathrm{Na}$ forma explicitada acima, nenhum experimento até agora demonstra evidências robustas, que possam auxiliar na indicação de um determinado tipo de medicamento para Covid-

Saúde. Pós-Graduação em Informação e Comunicação em Saúde, Rio de Janeiro, 2015.

20 Disponível em: https://bit.ly/2DADDii. Acesso em 22 jun. 2020. Cf. Disponível em: https://www.uab.edu/home/. Acesso em: 1 jul. 2020.

${ }^{21}$ O termo viés é a tendência em publicações científicas de evidências positivas terem maior probabilidade de serem publicadas do que evidências negativas. O resultado pode ser tendencioso. Cf. Diretrizes Metodológicas Sistema Grade - manual de graduação da qualidade da evidência e força de recomendação para tomada de decisão em saúde. Brasília, 2014, p.28/29. Disponível em: http://bvsms.saude.gov.br/bvs/publicacoes/diretrizes_metodologicas_sistema_grade.pdf. Acesso em: 1 jul. 2020.

22 MARTÍNEZ-SILVEIRA. Martha Silvia. Revisões sistemáticas como fonte de evidências científicas em Saúde. 2015. 185f. Tese (Doutorado) - Instituto de Comunicação e Informação Científica e Tecnológica em Saúde. Pós-Graduação em Informação e Comunicação em Saúde, Rio de Janeiro, 2015.

${ }^{23}$ NOGUEIRA, Roberto Henrique Porto. Responsabilidade Civil do Médico na Prescrição off label de medicamentos para Covid-19. 21 de abr. de 2020. Webinar Especial IBERC: "Coronavírus e Responsabilidade Civil". Disponível em: https://www.youtube.com/watch?v=TWAj8TZn8t0\&t= 17202s. Acesso em: 21 abr. 2020.

${ }^{24}$ Os termos randomizado e cego dizem respeito ao fato de que os grupos utilizados no experimento têm seus integrantes escolhidos de forma aleatória. 
19. Daí a dificuldade em se admitir a eficácia da Cloroquina e da Hidroxocloquina, com base em situações isoladas e sem fortes evidências.

De fato, na conclusão do Parecer 13/2004 emitido pelo Conselho Federal de Medicina, a prescrição de medicamentos, para fins terapêuticos, e que foram aprovados pela Anvisa para fins distintos, será considerada como "pesquisa médica combinada com cuidados profissionais (pesquisa clínica), sendo obrigatória a obtenção do consentimento livre e esclarecido do paciente" 25 . Por isso, recomenda-se que o médico sempre esteja atento às orientações do Ministério da Saúde, da Anvisa e do Conselho Federal de Medicina.

Muito embora essa seja a primeira recomendação, o entendimento de uma parte dos cientistas é o de que o emprego da Cloroquina, da Hidroxicloroquina e de suas associações com azitromicina não são recomendadas na rotina de tratamento da Covid-19. Neste sentido, aliás, manifestaram-se três entidades científicas brasileiras: Associação de Medicina Intensiva Brasileira, Sociedade Brasileira de Infectologia ${ }^{26}$ e Sociedade Brasileira de Pneumologia e Tisiologia. ${ }^{27} \mathrm{O}$ grupo de especialistas, que incluiu infectologistas, especialistas em medicina intensiva, pneumologistas, farmacêuticos, epidemiologistas e especialistas em saúde pública, identificou que o nível de evidências para uso da Cloroquina e da Hidroxicloroquina é fraca. De fato, uma coalizão formada com os principais hospitais do Brasil (Albert Einstein, HCor, SírioLibanês, Moinhos de Vento, Oswaldo Cruz, Beneficência Portuguesa, Brazilian Clinical Research Institute (BCRI) e pela Rede Brasileira de Pesquisa em Terapia Intensiva (BRICNet) destaca que a Cloroquina ${ }^{28}$ não beneficia pacientes com quadros leves e moderados ${ }^{29}$.

${ }^{25}$ Disponível em: https://sistemas.cfm.org.br/normas/visualizar/pareceres/BR/2004/13. Acesso em: 30 jun. 2020. Nesse sentido: Parecer CFM 482/2013.

26 Sociedade Brasileira de Infectologia. Disponível em: https://www.infectologia.org.br/admin/ zcloud/125/2020/03/c9b8d4f743ac65349e051b8638af7ee90d9a41f2f09a84f0ff83fc559fdf8b5f.pdf. Acesso em: 18 jun. 2020.

27 Disponível em: https://noticias.uol.com.br/saude/ultimas-noticias/redacao/2020/05/19/em-nova-diretrizsociedades-medicas-do-pais-recomendam-nao-usar-cloroquina.htm. Acesso em: 18 jun. 2020.

${ }^{28}$ Ana Paula Hermann, por sua vez, explica que "a cloroquina é um fármaco usado há muito tempo no tratamento da malária, uma doença causada por protozoários e transmitida por mosquitos. Já a Hidroxicloroquina é um derivado da cloroquina com as mesmas propriedades farmacológicas, mas menos efeitos tóxicos. HERRMANN, Ana Paula. Cloroquina contra o Coronavírus: existe evidência por trás da esperança. Disponível em: https://www.ufrgs.br/coronavirus/base/artigo-cloroquina-contra-o-coronavirusexiste-evidencia-por-tras-da-esperanca/. Acesso em: 17 jun. 2020. "Sintetizada em laboratório em 1934, a cloroquina deriva da quina, árvore usada por indígenas para curar febres muito antes da chegada dos europeus à América. Ingrediente de chás e outras receitas, entre elas a água tônica, foi com a malária que ganhou status de medicamento: descobriu-se que ela pode interferir no funcionamento dos lisossomos, organelas responsáveis pela digestão das células, e com isso aniquilar o causador da doença. "Ela se concentra no vacúolo alimentar ácido do parasita [causador da malária] e interfere nos processos essenciais", explica o farmacologista François Noel, professor do Instituto de Ciências Biomédicas da Universidade Federal do Rio de Janeiro (UFRJ). Nos glóbulos vermelhos, ela se liga ao heme [átomo de ferro] formando um complexo tóxico que mata a célula e o parasita. Já a hidroxicloroquina é uma versão aprimorada e menos tóxica da cloroquina, indicada para tratamentos de longo prazo. Desenvolvida em 1946, ela é aplicada nas terapias de doenças autoimunes como artrite reumatoide e lúpus, além dos casos em que a malária é provocada por protozoários resistentes à cloroquina. Em 2007, pesquisadores liderados pelo infectologista Didier Raoult, da Universidade de Medicina de Marselha, na França, fizeram testes in vitro para demonstrar que a cloroquina e a hidroxicloroquina poderiam ser usadas contra infecções bacterianas, fúngicas e virais - entre elas, o HIV e o Sars-CoV-1 (coronavírus causador da Sars, síndrome respiratória que surgiu na China em 2002). Além de atuarem nos lisossomos e, com isso, prejudicarem a replicação do vírus (ele depende das células humanas para se reproduzir), as drogas interferem nas enzimas que convertem a proteína na cápsula do vírus (que parecem "espinhos") e permitem a entrada nas 
O que despertou o interesse pelo uso desses medicamentos no Brasil, foram estudos realizados na China e na França, que apontam que grupos de pacientes com a Covid-19, submetidos a tratamento com Hidroxicloroquina em conjunto com outros medicamentos tiveram redução na carga viral ${ }^{30}$. Por conta das análises feitas nesses países, mesmo os resultados não tendo sido definitivos sobre o potencial benefício no uso da Cloroquina e da Hidroxicloroquina no tratamento da Doença da Covid-19, a Anvisa emitiu nota técnica sobre o assunto, e afirmou que haveria "evidência pré-clínica da eficácia e evidência de segurança do uso clínico de longa data para outras indicações, o que justifica a pesquisa clínica com a Cloroquina em pacientes com COVID-19". ${ }^{31}$

A própria Anvisa, porém, não recomenda o uso indiscriminado desses medicamentos sem a confirmação de que realmente funcionam, pois "os estudos conduzidos até o momento têm um número de pacientes muito reduzido e ainda é arriscado afirmar que vai funcionar no tratamento da Covid-19". E ainda afirma que "mais dados precisam ser coletados, de maneira adequada, para haver certeza de que vai funcionar". ${ }^{32}$

Já o Conselho Federal de Medicina alertou que "embora novos protocolos e vacinas estejam em fase de análise [...], não há estudos conclusivos que comprovem a eficácia e segurança do uso de medicamentos que contêm cloroquina e hidroxicloroquina para o tratamento da Covid-19". ${ }^{33}$

A Organização Mundial de Saúde também assinala que, além de não haver comprovação da eficácia do remédio no tratamento contra a Covid-19, ele causa efeitos colaterais perigosos, principalmente para quem tem problemas no coração. ${ }^{34}$

Diante de todas essas discussões e incertezas, em março de 2020, o Conselho Nacional de Justiça (CNJ) encomendou Parecer Técnico ao Hospital Sírio Libanês sobre o uso da Hidroxicloroquina ${ }^{35}$. De acordo com o documento "a eficácia e a segurança dos medicamentos em pacientes com Covid-19 são incertas e seu uso de rotina para esta situação

células". Disponível em: https://revistagalileu.globo.com/Ciencia/Saude/noticia/2020/05/os-riscos-dacloroquina-e-da-hidroxicloroquina-no-tratamento-da-covid-19.html. Acesso em 18 Jun. 2020.

${ }^{29}$ BERGAMO, Mônica. Maior Estudo do país vê hidroxocloroquina ineficaz contra Covid. Folha de S. Paulo, São Paulo, ano 100, n. 33.250, 24 de jul. de 2020. Saúde, p. B2.

30 Disponível:https://www.cnnbrasil.com.br/saude/2020/04/06/hidroxicloroquina-o-que-e-o-medicamento-epor-que-ele-divide-o-governo. Acesso em: 15 jun. 2020.

31 VENAGLIA, Guilherme. Hidroxicloroquina: o que é o remédio e por que ele divide médicos e políticos. Disponível em: http://portal.anvisa.gov.br/documents/219201/4340788/Nota+Técnica+sobre+Cloroquina+ e+Hidroxicloroquina.pdf/659d0105-60cf-4cab-b80a-fa0e29e2e799. Acesso em: 13 jun. de 2020.

32 Disponível em: http://portal.anvisa.gov.br/coronavirus/faq. Nota 14. Acesso em: 18 jun. 2020.

33 Disponível em: http://portal.cfm.org.br/index.php?option=com_content\&view=article\&id=28637:2020-0320-18-20-23\&catid=3 Acesso em: 16 jun. 2020. Cf. https://revistagalileu.globo.com/Ciencia/Saude/ noticia/2020/05/os-riscos-da-cloroquina-e-da-hidroxicloroquina-no-tratamento-da-covid-19.html. Acesso em: 18 jun. 2020.

34 Anvisa. Nota Técnica sobre Cloroquina e Hidroxicloroquina. Disponível em: http://portal.anvisa.gov.br/documents/219201/4340788/Nota+Te\%C2\%B4cnica+sobre+Cloroquina+e+Hidro xicloroquina.pdf/659d0105-60cf-4cab-b80a-fa0e29e2e799>. Acesso em 13 Jun. 2020. V. ainda a posição do Conselho Federal de Medicina. Disponível em: http://portal.cfm.org.br/index.php?option= com_content\&view=article\&id=28637:2020-03-20-18-20-23\&catid=3. Acesso em: 16 jun. 2020.

35 PACHECO, Rafael Leite; RIEIRA, Rachel. Hidroxicloroquina para Infecção por Covid-19. 20 de mar. de 2020. Disponível em: https://www.cnj.jus.br/e-natjus/arquivo-download.php?hash=3662fc98904c4e522 96b31c6d21c5ebabfef6cb9. Acesso em: 10 jun. 2020. 
não pode ser recomendado até que os resultados dos estudos em andamento possam avaliar seus efeitos de modo apropriado"36.

Foi destacado, ainda, no referido parecer que "a falta deste medicamento para pacientes portadores de doenças para as quais a Hidroxicloroquina está formalmente indicada incluindo doenças crônicas autoimunes como lúpus eritematoso sistêmico e artrite reumatoide já é uma realidade". ${ }^{37}$ Assim, ao tempo que se deseja aplicar essa medicação para tratar a Covid-19, outros danos podem advir para portadores de outras doenças que necessitam, efetivamente, desse medicamento, uma vez que ele poderá faltar.

Mister chamar atenção para o fato de que, em abril de 2020, o Conselho Federal de Medicina (CFM) divulgou Parecer $n^{\circ}$ 04/202038, no qual estabelece critérios e condições para a prescrição de Cloroquina e de Hidroxicloroquina em pacientes com diagnóstico confirmado de Covid-19. Esta decisão aqueceu ainda mais o debate acerca do possível tratamento para a doença, mesmo que não existam comprovações científicas de que sejam eficazes.

O resultado desse posicionamento do Conselho Federal de Medicina seguiu no rastro da elaboração de Protocolo por parte do Ministério da Saúde frente a pressões econômicas e políticas surgidas naquele momento. Diante daquele cenário, em maio de 2020, o governo brasileiro anunciou um novo Protocolo para o uso dos referidos medicamentos, ampliando a recomendação de seu uso, passando a incluir não só os casos graves da Covid-19, mas, também, os considerados leves.

Enfim, não obstante as dúvidas sobre uma evidência científica que confira eficácia à Cloroquina ou à Hidroxicloroquina contra a doença Covid-19, o Ministério da Saúde ${ }^{39}$, no

\footnotetext{
${ }^{36}$ Resumo do Parecer Técnico 123: "Contexto: Com base em resultados de estudos preliminares, o uso offlabel de hidroxicloroquina para infecção por COVID-19 tem sido observado na prática. Objetivos: Identificar, avaliar sistematicamente e sumarizar as melhores evidências científicas disponíveis sobre a eficácia e a segurança do uso da hidroxicloroquina e cloroquina para infecção por COVID-19. Métodos: Revisão sistemática rápida (rapid review methodology). Resultados: Após o processo de seleção, 17 estudos foram incluídos: um estudo clínico em andamento com dados parciais publicados e 16 estudos em andamento sem dados publicados. Os dados de eficácia foram restritos a um único estudo, com 42 participantes que avaliou apenas a detecção viral (desfecho intermediário). O estudo possui sérias limitações metodológicas e apresenta risco de viés sério pela ferramenta ROBINS-I. Nenhum dado de segurança foi apresentado pelo estudo. A avaliação da certeza da evidência pela ferramenta GRADE não foi realizada devido à ausência de desfechos clínicos relevantes. Conclusão: Com base nos achados nesta revisão sistemática rápida, a eficácia e a segurança da hidroxicloroquina e da cloroquina em pacientes com COVID-19 é incerta e seu uso de rotina para esta situação não pode recomendado até que os resultados dos estudos em andamento possam avaliar seus efeitos de modo apropriado." Disponível em: https://www.cnj.jus.br/enatjus/arquivo-download.php?hash=3662fc98904c4e52296b31c6d21c5ebabfef6cb9. Acesso em: 15 jun. 2020. O parecer está disponível no e-NATJus Nacional. É relevante o parecer do Hospital Sírio Libanês estar naquela Plataforma porque permite que os magistrados se orientem na tomada de decisões com pedidos para fornecimento desse medicamento: Hidroxicloroquina.

${ }^{37}$ HOSPITAL SÍRIO LIBANÊS. Hidroxicloroquina para Infecção por Covid-19. 20 de mar. de 2020. Disponível em: https://www.cnj.jus.br/e-natjus/arquivo-download.php?hash=3662fc98904c4e52296b31c6d 21c5ebabfef6cb9. Acesso em: 10 jun. 2020.

${ }^{38}$ Disponível em: https://portal.cfm.org.br/index.php?option=com_content\&view=article\&id=28672:2020-0423-13-08-36\&catid=3. Acesso em: 11 jun. 2020.

${ }^{39}$ Ministério da Saúde divulga diretrizes para tratamento medicamentoso de pacientes. Site Ministério da Saúde. 20 de Maio de 2020. Disponível em: https://www.saude.gov.br/noticias/agencia-saude/46919ministerio-da-saude-divulga-diretrizes-para-tratamento-medicamentoso-de-pacientes. Acesso em: 11 jun. 2020.
} 
Protocolo que se encontra atualmente em vigor, valeu-se do posicionamento do Conselho Federal de Medicina, e autorizou que médicos as receitem a seus pacientes:

A prescrição de todo e qualquer medicamento é prerrogativa do médico, e que o tratamento do paciente portador de COVID-19 deve ser baseado na autonomia do médico e na valorização da relação médico-paciente que deve ser a mais próxima possível, com objetivo de oferecer o melhor tratamento disponível no momento. ${ }^{40}$

Na prática, com o novo Protocolo, o governo autoriza que médicos da rede pública de saúde receitem a Cloroquina associada ao antibiótico azitromicina logo após os primeiros sintomas da doença, como coriza, tosse e dor de cabeça. As doses dos medicamentos são alteradas conforme o quadro de saúde ${ }^{41}$. Aduza-se que o documento divulgado pelo Ministério da Saúde faz algumas ressalvas. Entre elas, que o medicamento deve ser prescrito por um médico, além do fato de ele ter autonomia para decidir ou não sobre o seu uso ${ }^{42}$, com consentimento informado e esclarecido de seu paciente. (V. item 3, infra).

O texto afirma, ademais, que atualmente "não existe outro medicamento eficaz disponível para o tratamento do novo coronavírus, e que não recomenda a auto prescrição do remédio pelo portador da doença (uso sem acompanhamento médico)". E, mais: "A divulgação do novo protocolo pretende uniformizar as orientações para os profissionais do SUS para o tratamento da Covid-19, sendo que o objetivo é ampliar o acesso dos pacientes à Cloroquina e Hidroxicloroquina no SUS". ${ }^{43}$

Ressalte-se que, além da autorização do uso das medicações aqui mencionadas, foi igualmente divulgado pelo Ministério da Saúde, um modelo do termo de ciência e consentimento ${ }^{44}$ que deverá ser assinado pelo paciente para aceitar a prescrição, com benefícios e riscos do medicamento.

Ao final, todos os órgãos apontados acima comungam do entendimento de que não há nenhuma pesquisa finalizada que ateste a eficácia e segurança das medicações, e ainda convergem que não é permitida a prescrição combinada de Hidroxicloroquina e Cloroquina de modo indiscriminado. Isto significa que, qualquer conduta irrefletida e desmedida no seu emprego, pode resultar na responsabilização do médico nas esferas civil, penal e administrativa.

Em resumo, o que se constata é que os vários estudos clínicos em curso, que versam sobre a aplicação da Cloroquina e da Hidroxicloroquina no tratamento da SARS-CoV-2, mostram

40 TERESINA, Bárbara Rodrigues. Ministério da Saúde libera cloroquina para todos pacientes com covid19. GP1. 20 de maio de 2020. Disponível em: https://www.gp1.com.br/noticias/ministerio-da-saude-liberacloroquina-para-todos-pacientes-com-covid-19-478237.html. Acesso em: 15 jun. 2020.

41 Disponível em: https://www.saude.gov.br/noticias/agencia-saude/46919-ministerio-da-saude-divulgadiretrizes-para-tratamento-medicamentoso-de-pacientes. Acesso em: 19 jun. 2020.

42 Disponível em: https://www.saude.gov.br/noticias/agencia-saude/46919-ministerio-da-saude-divulgadiretrizes-para-tratamento-medicamentoso-de-pacientes. Acesso em: 19 jun. 2020.

43 Disponível em: https://www.cnnbrasil.com.br/saude/2020/05/20/governo-muda-protocolo-e-autorizahidroxicloroquina-para-casos-leves-de-covid-19. Acesso em: 18 jun. 2020.

${ }^{44}$ FARFAN, Tainá. Governo muda protocolo e autoriza hidroxicloroquina para casos leves de Covid-19. Disponível em: https://www.cnnbrasil.com.br/saude/2020/05/20/governo-muda-protocolo-e-autoriza-hidroxi cloroquina-para-casos-leves-de-covid-19. Acesso em: 18 jun. 2020. 
que o estado da arte é o de que ainda não há evidências científicas suficientes que validem sua eficácia e sua segurança em seres humanos acometidos pelo novo coronavírus. ${ }^{45}$ Pelo contrário. Na visão da renomada revista British Medical Journal (BMJ) foi enfatizado em seu editorial de 8 de abril de 2020 que "o uso dessas drogas é prematuro e potencialmente prejudicial"46.

Nesse panorama temerário e de perplexidade, amplia-se o dever de cautela dos médicos nas prescrições do medicamento autorizado pelo Ministério da Saúde em maio de 2020, inclusive, transpondo os cuidados determinados por este órgão. ${ }^{47}$

\section{DO PATERNALISMO HIPOCRÁTICO À AUTONOMIA EXISTENCIAL DO PACIENTE}

Para que o paciente, diante do acima exposto, possa consentir com o uso da Cloroquina ou da Hidroxicloroquina, faz-se importante traçar algumas notas sobre a passagem do paternalismo hipocrático para a autonomia existencial, demonstrando-se o quão imperiosa se mostra sua manifestação de vontade, no sentido do emprego das medicações referidas.

Um dos pontos centrais da chamada bioética principialista, surgida nos Estados Unidos, nos anos 1970 do século XX, a partir do famoso relatório Belmont (1974) ${ }^{48}$, e consolidada por Tom L. Beauchamp e James F. Childress ${ }^{49}$, tem a ver com o princípio do respeito à autonomia do paciente..$^{50}$ Este encontra seu fundamento nos experimentos feitos com

45 OMS suspende o uso da cloroquina e hidroxicloroquina em testes contra a Covid-19. Portal PEBMED. Disponível em: https://pebmed.com.br/oms-suspende-o-uso-da-cloroquina-e-hidroxicloroquina-em-testescontra-a-covid-19/. Acesso em: 1 jul. 2020. Cf. WATANABE, Phillippe. The Lancet faz retratação de estudo que apontava maior risco de morte associado à hidroxicloroquina. Disponível em: https://www1 folha.uol.com.br/equilibrioesaude/2020/06/the-lancet-retrata-estudo-que-apontava-maior-riscode-morte-associado-a-hidroxicloroquina.shtml. Acesso em: 1 jul. 2020.

46 BMJ. Chloroquine and hydroxychloroquine in Covid-19. BMJ, 8 abr. 2020. Disponível em: https://doi.org/10.1136/bmj.m1432. Acesso em: 17 jun. 2020.

${ }^{47}$ Nessa direção, confira-se o parecer da Sociedade Brasileira de Infectologia, "que considera o uso da hidroxicloroquina para tratamento da covid-19 como uma "terapia de salvamento experimental". Seu uso deve ser individualizado e avaliado pelo médico prescritor, preferencialmente com a participação de um infectologista, avaliando seus possíveis efeitos colaterais e eventuais benefícios. Entre os principais efeitos adversos, destacam-se: discrasia sanguínea, distúrbios gastrintestinais (náuseas, vômitos, diarreia), fraqueza muscular, labilidade emocional, erupções cutâneas, cefaleia, turvação visual, descoloração do cabelo ou alopecia e tontura. Recomendamos que, se usado, idealmente o seja na forma de estudo clínico aprovado pela Comissão Nacional de Ética em Pesquisa (CONEP) ou, para resguardar o médico prescritor, que pelo menos seu uso seja aprovado pelo Comitê de Ética do hospital, com termo de consentimento do paciente ou da família (paciente intubado). Como é uma medicação experimental para esta indicação (covid-19), é importante que seu eventual uso seja dentro de um protocolo da instituição e que os resultados, tanto se forem positivos, como negativos, sejam relatados. A SBI acha compreensível seu uso no paciente crítico, já que não há tratamento aprovado para covid-19, mas manifesta sua preocupação que um tratamento experimental possa trazer mais danos do que benefícios para o paciente." Disponível em: https://www.infectologia.org.br/admin/zcloud/125/2020/03/c9b8d4f743ac65349e051b8638af7ee90d9a41f2f0 9a84f0ff83fc559fdf8b5f.pdf. Acesso em: 16 jun. 2020.

48 Disponível em: https://www.hhs.gov/ohrp/regulations-and-policy/belmont-report/read-the-belmont-report/ index.html. Acesso em: 3 jul. 2020.

49 DINIZ, Debora. GUILHERM, Dirce. O que é bioética? São Paulo: Brasiliense, 2007, p. 25.

${ }^{50}$ Além desse princípio ainda há os da justiça, da beneficência, e da não-maleficência, tendo estes dois últimos sido desmembrados do princípio da beneficência, por Tom L. Beauchamp e James F. Childress, Sobre eles: BEAUCHAMP, Tom L.. CHILDRESS, James F. Princípios de Ética Biomédica. 2. ed. Tradução de Luciana Pudenzi. São Paulo: Loyola, 2011, p. 137 e s. V., ainda a Introdução brasileira escrita por Leo 
seres humanos durante a Segunda Grande Guerra na Alemanha, e que levou a um primeiro documento internacional sobre o tema, o chamado Código de Nuremberg ${ }^{51}$. A partir daí, tem início um movimento de mudança na relação entre médico e paciente, que não ocorrerá do dia para a noite, pelo qual a vontade do paciente passa a ter relevância, devendo ser respeitada pelo profissional da saúde. O chamado paternalismo hipocrático, portanto, começa a declinar. Neste sentido é que vale a pena transcrever a lição de José Marques Filho sobre paternalismo, para que se possa verificar o que significou deixá-la para trás, em favor da autonomia do paciente:

$\mathrm{Na}$ área médica, da metade do século $\mathrm{XIX}$ até a metade do século $\mathrm{XX}$, os pacientes mantiveram seu tradicional papel de passividade na relação com seu médico. Nesse período, o tradicional paternalismo hipocrático adquiriu contornos que podem ser comparados aos paternalismos brando e forte de Feinberg. No paternalismo brando, o médico vocacionado, com uma visão holística do paciente, o vê como um ser com uma unidade cósmica e espiritual. A assistência médica é caracterizada pela amizade - a velha philia grega - e pelo paternalismo benevolente de Hipócrates. O paternalismo forte é característico dos médicos que veem o paciente somente como um ser de natureza cósmica - o conhecimento científico provê o médico de poder quase absoluto e reduz o doente a um ser dotado de incompetência física e moral. Contudo, o paternalismo tem uma longa e marcante história na prática médica, iniciando de forma paradigmática com o 'pai da Medicina'. Hipócrates, lastreado nos conhecimentos filosóficos de sua época, praticou e divulgou em suas andanças e por meio de suas obras e ensinamentos aos seus discípulos o que conhecemos até hoje como 'conduta paternalista do médico', ou seja 'eu sou o médico e sei o que é bom para você, assim como um pai sabe o que é bom para um filho, pois detenho o conhecimento e o saber; não irei prejudicá-lo, pretendo fazer o bem para você, portanto, obedeça e não me questione. O paternalismo foi uma consequência natural do princípio ético da beneficência, um dos pilares do famoso juramento hipocrático. Esse princípio, não se pode esquecer, seria praticado dentro da visão cultural, social e política da época. ${ }^{52}$

A partir desta breve explanação sobre o paternalismo, constata-se que, no estágio atual da sociedade, em que o princípio da dignidade da pessoa humana há de imperar - o que é

Pessini, em especial p. 11 e s. Debora Diniz e Dirce Guilhem explicam, ademais, sobre o relatório Belmont: "Os participantes do Relatório Belmont justificaram a eleição de três princípios éticos, dentre um universo de possibilidades, argumentando que a escolha baseava-se em uma estrutura profunda do pensamento moral. Para eles, os princípios éticos escolhidos pertenciam à história das tradições morais do ocidente, havendo uma relação de dependência mútua entre eles, fato que garantia sua harmonia quando aplicados". DINIZ, Debora. GUILHERM, Dirce. O que é bioética? São Paulo: Brasiliense, 2007, p. 22.

51 Conforme a lição de José Marques Filho: "Na área médica, a autonomia somente foi reconhecida formalmente no Código de Nuremberg, após as atrocidades cometidas pelos nazistas em pesquisas com seres humanos, durante a Segunda Guerra Mundial." MARQUES FILHO, José. Relação Médico-Paciente Autonomia ou Paternalismo? In: PEREIRA FILHO, Antônio. MARQUES FILHO, José. (Coords.). Bioética: Dilemas e Diálogos Contemporâneos. São Paulo: Cremesp, 2018, p. 182. Vale a pena, ainda, mencionar os escritos de Brunello Souza Stancioli sobre o tema: "O Código de Nurembeg pode ser colocado como o grande marco da resposta ético-jurídica às intervenções médicas não autorizadas. Esse Código foi promulgado em 1948, como parte do julgamento Estados Unidos vs. Karl Brand, um dos médicos nazistas. Dentre outras acusações, o médico respondeu pelas intervenções 'médicas' nas quais obrigava seus 'pacientes' a ingerirem venenos, a tomarem doses de gasolina intravenosa, a serem imersos em água gelada etc.". STANCIOLI, Brunello Souza. Relação Jurídica Médico-Paciente. Belo Horizonte: Del Rey, 2004 , p. 52.

52 MARQUES FILHO, José. Relação Médico-Paciente - Autonomia ou Paternalismo? In: PEREIRA FILHO, Antônio. MARQUES FILHO, José. (Coords.). Bioética: Dilemas e Diálogos Contemporâneos. São Paulo: Cremesp, 2018, p. 183. 
realidade para o ordenamento jurídico brasileiro, basta ler o inciso III do art. $1^{\circ}$ da Constituição da República -, não há mais lugar para a sujeição do paciente à vontade pura e simples do médico. ${ }^{53}$ Ele pode deter o conhecimento científico e a técnica para executar o que se faz necessário para tratar o doente, mas este tem de concordar com os métodos que serão empregados em sua pessoa, podendo, inclusive, negar-se tanto a submeter-se a um tratamento médico, quanto a tomar conhecimento sobre o mal que the acomete.

À esta autonomia que o paciente passa a ter, costuma-se designar, hodiernamente, de autonomia existencial. Esta classificação vem dos estudos desenvolvidos por Antonio Junqueira de Azevedo, acerca dos contratos de lucro e dos contratos existenciais. ${ }^{54}$ Naqueles ter-se-ia como fundamento o patrimônio dos contraentes; nestes, por sua vez, questões relacionadas à pessoa, como ocorre nos contratos com convênio médicos. Assim é que o campo dos direitos de personalidade, é o ideal para o exercício dessa nova forma de autonomia, designada de "existencial". 55

Enfim, a autonomia que a pessoa passa a exercer em relação ao seu corpo, a partir do momento em que o paternalismo hipocrático sai de cena, e ela entra na história para ser sua própria protagonista, torna-a, de certa forma, independente da mera vontade do profissional da saúde. Este, contudo, não perde seu papel, mas, desta feita, ele passa a coadjuvante no que diz respeito ao processo decisório, devendo informar e amparar o doente a tomar a melhor decisão possível para o seu caso. Desse modo, em razão da Cloroquina e da Hidroxicloroquina não serem medicamentos que demonstrem, por meio das evidências científicas que até o momento se dispõem, um benefício inequívoco para o paciente - outro princípio da bioética -, mas eventualmente, um mal, em razão dos efeitos colaterais que poderá causar, o consentimento informado e esclarecido do paciente é imprescindível. Neste sentido, inclusive, o Protocolo do Ministério da Saúde (v. nota de rodapé n. 39, supra), que menciona a autonomia do médico para prescrever a droga, mas levando em consideração a relação médico-paciente.

\section{CONSENTIMENTO INFORMADO E ESCLARECIDO, TRANSPARÊNCIA E PODER DE DECISÃO DO PACIENTE}

Inserido no campo do direito à saúde encontra-se a relação médico-paciente, posto ser o médico, na sociedade contemporânea, o profissional indicado a cuidar dos problemas que

\footnotetext{
53 Sobre essa problemática v.: STANCIOLI, Brunello Souza. Relação Médico-Paciente. Belo Horizonte: Del Rey, 2004, em especial p. 23 e s. O autor desenvolve ao longo de seu texto todo o processo que levou à autonomia da pessoa na relação médico-paciente.

${ }^{54}$ Cf. AZEVEDO. Antonio Junqueira de. (Parecer) Natureza jurídica do contrato de consórcio (sinalagma indireto). Onerosidade excessiva e em contrato de consórcio. Resolução parcial do contrato. In: AZEVEDO, Antonio Junqueira de. Novos Estudos e Pareceres de Direito Privado. São Paulo: Saraiva, 2009, p. 356.

${ }^{55}$ Para uma análise mais aprofundada sobre a autonomia existencial v.: GOZZO, Débora; MONTEIRO, Juliano Ralo. A concretização da autonomia existencial e a Lei n. 13.146/15: apontamentos sobre o casamento da pessoa com deficiência. Civilistica.com, Rio de Janeiro, a. 8, n. 1, 2019. Disponível em: http://civilistica.com/wp-content/uploads/2019/04/Gozzo-e-Monteiro-civilistica.com-a.8.n.1.2019.pdf. Acesso em: 30 jun. 2020.
} 
acometem o físico e a mente da pessoa. O paciente, contudo, não é mais parte passiva nessa relação, como restou demonstrado no item anterior. Cabe a ele, diferentemente do que já ocorreu muito no passado, o poder de consentir ou não com as práticas médicas que forem propostas pelo médico. Por isso é que se fala no consentimento informado e esclarecido. Compete ao médico informar o paciente da melhor forma possível, como afirma o art. 34 do Código de Ética Médica, sobre o "diagnóstico, o prognóstico, os riscos e os objetivos do tratamento, salvo quando a comunicação direta possa lhe provocar dano, devendo, nesse caso, fazer a comunicação a seu representante legal”. ${ }^{56}$ Assim é que já se constata que o consentimento informado e esclarecido tem função primordial na relação de consumo que se estabelece entre o médico e o paciente. Ele é o instrumento pelo qual o médico pode e, deve, levando em consideração a autorização do paciente, dimensionar os limites do tratamento a ser imposto a determinada pessoa que está sob seus cuidados em razão de problemas de saúde.

No mesmo sentido desta norma deontológica do Código de Ética Médica, encontra-se o art. 15 do Código Civil, ao determinar que "[n]inguém pode ser constrangido a submeter-se, com risco de vida, a tratamento médico ou a intervenção cirúrgica". Pela simples leitura do dispositivo legal tem-se a impressão de que, se fosse sem risco de vida, o paciente poderia ser obrigado a submeter-se a tratamento médico, sem desejá-lo. Assim é que Nelson Rosenvald e Felipe Braga Neto advertem que, a despeito da má redação do texto legal, não é assim que ele deve ser interpretado, além de seu tema remeter "à questão do consentimento informado. (...)". ${ }^{57}$ Assim, afirmam ainda os autores:

\begin{abstract}
Esclareça-se que não se admite consentimentos para a prática de danos, quaisquer que sejam (estamos diante da saúde humana, em sua indissociável integralidade). Afirmar isso não equivale a negar qualquer validade para 0 chamado consentimento informado. O consentimento informado - cujo ônus da prova caberá sempre ao médico ou à instituição de saúde - poderá conforme o caso, ostentar prestabilidade jurídica, desde que o procedimento ou tratamento seja adequado e proporcional, diante da situação fática posta. Não, porém, como mero formulário padrão, mas como dever de informar - bem, leal e concretamente - acerca dos riscos e possibilidades do tratamento. Nesse contexto, o formulário poderá, também, ser usado, mas não imuniza de modo absoluto, a responsabilidade civil dos médicos ou planos de saúde diante da informação falha, defeituosa ou omissa. (grifos do original) ${ }^{58}$
\end{abstract}

Constata-se, pois, que tanto o Código de Ética Médica, quanto o Código Civil disciplinam na mesma direção, isto é, a da necessidade de um consentimento informado.

Mas, qual o motivo de o substantivo consentimento ser adjetivado pelo termo "informado"?

Desde que se deixou a fase de hegemonia do princípio paternalista, pelo qual o médico seria o detentor do conhecimento capaz não só de beneficiar, mas também de não causar um

${ }^{56}$ Disponível em: http://portal.cfm.org.br/images/PDF/cem2019.pdf. Acesso em: 3 Jul. 2020.

${ }^{57}$ ROSENVALD, Nelson. BRAGA NETTO, Felipe. Código Civil Comentado. Salvador: Juspodivm, 2020, p. 87.

${ }^{58}$ ROSENVALD, Nelson. BRAGA NETTO, Felipe. Código Civil Comentado. Salvador: Juspodivm, 2020, p. 88. 
malefício ${ }^{59}$ ao paciente, competindo a este aceitar os desígnios daquele, passou-se a entender que o paciente deveria ter um papel mais ativo, nessa relação. Afinal, trata-se da sua pessoa e seu corpo e/ou psique, que necessitam de cuidados. Compete, pois, a ele decidir, a partir da informação que lhe for prestada pelo médico, sobre como quer ser tratado. Isto só foi possível, como visto no item anterior, a partir do momento em que sua liberdade de decidir, sua autonomia - princípio bioético, inclusive -, passa a ter relevância.

De modo geral, só a pessoa bem informada é capaz de tomar a decisão que julga ser a mais acertada para sua vida. E, toda pessoa tem o direito não só de ser informada, como também de buscar a informação, se entender que ainda não compreendeu bem o que lhe está sendo transmitido. No fundo, na relação médico-paciente, o médico é o detentor dessa informação, e tem o dever de transmiti-la ao paciente, auxiliando-o a entender seu caso e o tratamento ao qual poderá vir a ser submetido. Poderá ser, porque o paciente tem o direito de rechaçá-lo ${ }^{60}$, se entender que isso não é o melhor para ele nesse momento. Antes desse movimento, da passagem do paternalismo médico para a autonomia do paciente ( $v$. item 3, supra), esse tipo de atitude por parte do paciente seria impensável, como visto no item supra. Essa informação é, aliás, "um processo contínuo que deve ser transmitido com antecedência suficiente para que o paciente possa ponderar e absorver os riscos e benefícios da intervenção em seu corpo que no sistema jurídico". ${ }^{61}$

Além de todo esse processo, e, voltando-se ao dever de informar perante o ordenamento jurídico brasileiro, ele "se desenvolveu como um dever lateral decorrente do princípio da boa-fé objetiva, em verdadeiro processo colaborativo entre as partes. Isto porque, o direito à informação está diretamente relacionado com a liberdade de escolha daquele que consome."62

Mas não é só de informação que se cuida, quando o tema é o do consentimento do paciente. Entra em jogo, aqui, igualmente, o direito do paciente de ser informado de maneira esclarecida. Para que isto ocorra, a informação tem de ser transparente. E isto só ocorre quando a linguagem empregada pelo médico, no momento de transmitir a informação, não só for clara, nítida (elemento objetivo) ${ }^{63}$, mas também for passível de ser compreendida (elemento subjetivo $)^{64}$ pelo paciente. Assim é que, a expressão clareza está umbilicalmente ligada às

59 Princípio bioético da não maleficência.

60 ABEJA, Laura Gómez. El derecho a rechazar el tratamiento médico: Análisis de los antecedentes desde una perspectiva constitucional. Valencia: Tirant, 2014, em especial, p. 36 e s., sobre pessoa capaz.

$61 \mathrm{GOZZO}$, Débora; MONTEIRO, Juliano Ralo. O idoso com demência senil ou deficiente mental na relação jurídica médico-paciente. In: ROSENVALD, Nelson. BEZERRA DE MENEZES, Joyceane. DADALTO, Luciana. (Coord.). Responsabilidade Civil e Medicina. Indaiatuba: Foco, 2020, p. 92.

62 GOZZO, Débora; MONTEIRO, Juliano Ralo. O idoso com demência senil ou deficiente mental na relação jurídica médico-paciente. In: ROSENVALD, Nelson. BEZERRA DE MENEZES, Joyceane. DADALTO, Luciana. (Coord.). Responsabilidade Civil e Medicina. Indaiatuba: Foco, 2020, p. 92.

${ }^{63}$ GOZZO, Débora. Transparência, informação e a relação médico-paciente. In: GOZZO, Débora (Coord.). Informação e Direitos Fundamentais: a eficácia horizontal das normas constitucionais. São Paulo: Saraiva, 2012, p. 83.

64 GOZZO, Débora. Transparência, informação e a relação médico-paciente. In: GOZZO, Débora (Coord.). Informação e Direitos Fundamentais: a eficácia horizontal das normas constitucionais. São Paulo: Saraiva, 2012, p. 83. 
palavras usadas pelo profissional da saúde. Elas devem ser conhecidas do paciente. O médico deve saber quem é seu paciente, e adaptar seu vocabulário a ele. Desse modo, se o médico fizer uso de linguagem técnica, a não ser que o paciente também seja da área, ele pouco terá chance de reconhecer as palavras usadas pelo médico. Isto de fato não é o que se almeja, quando se emprega a expressão "consentimento informado e esclarecido". Mas, além de o vocabulário do profissional ter de ser adaptado ao do paciente, a informação tem de ser ministrada de tal forma, que ele possa compreender o que lhe está sendo transmitido. Se o paciente não conseguir entender o sentido de tudo o que lhe está sendo informado, porque ele não é capaz de relacionar os fatos que lhe estão sendo apresentados de uma maneira una, seu consentimento não deverá ser considerado esclarecido.

Importante, ainda, quanto ao consentimento e à autonomia existencial do paciente, fazer-se uma distinção entre a capacidade negocial e a de entendimento, como explicita Bruno Souza Stancioli. Aquela está prevista nos arts. $3^{\circ}$., e $4^{\circ}$., I da lei civil. "Não há que se perquirir o grau de cognição, ou entendimento, da pessoa natural, que não se enquadre nas idades fixadas normativamente. Os critérios são objetivos e inflexíveis." ${ }^{65}$. Nesta, isto é, a capacidade de entendimento, observa-se "o domínio cognitivo e habilidade decisional, ou 'poder de avaliar, julgar". ${ }^{66}$ Nas suas palavras:

\begin{abstract}
Essa capacidade leva em conta, portanto, o ethos crítico da pessoa natural, tendo em vista sua maturidade e educação. Não apresenta critérios objetivos, mas deve ser avaliada de forma situacional. Em outras palavras, busca-se analisar se o indivíduo tem capacidade para uma atividade determinada. A capacidade de entendimento tem, portanto, uma imbricação muito mais íntima com a autonomia da vontade. (Grifos nossos) ${ }^{67}$
\end{abstract}

O papel da vontade, portanto, encontra-se demarcado na relação médico-paciente de forma indelével, cabendo ao paciente declará-la, exercendo por completo sua capacidade de entendimento. Isto porque, com a informação tendo sido transmitida com transparência, o paciente encontra-se em condições de exercer livremente sua autonomia existencial, porquanto ele está tomando decisões sobre seu corpo, sobre sua saúde, enfim, sobre sua esfera pessoal, não patrimonial. Isto, desde que ele esteja em condições de se autodeterminar, uma vez que em alguns casos, em razão de sua vulnerabilidade, isto não será possível. Assim, quando o paciente for menor abaixo dos dezesseis (16) anos (CC, art. $3^{\circ}$.), a decisão competirá ao representante legal. Se ele já for relativamente capaz, entre os dezesseis (16) anos completos e os dezoito (18) incompletos (CC, art. $4^{\circ}$., caput), deverá ser ouvido, mas a validade de seu consentimento dependerá da anuência de seu assistente legal, cabendo a qualquer um deles recorrer ao Judiciário, caso haja discordância quanto ao exercício do poder familiar (CC, art. 1.692)68.

${ }^{65}$ STANCIOLI, Bruno Souza. Relação Médico-Paciente. Belo Horizonte: Del Rey, 2004, p. 46.

66 STANCIOLI, Bruno Souza. Relação Médico-Paciente. Belo Horizonte: Del Rey, 2004, p. 46.

67 STANCIOLI, Bruno Souza. Relação Médico-Paciente. Belo Horizonte: Del Rey, 2004, p. 46.

68 Defende-se aqui o entendimento de que se o menor pode recorrer ao Judiciário, na eventualidade de discordar de seus pais sobre o exercício do poder familiar, no que diz respeito aos seus bens, por que não 
No concernente ao maior acima dos sessenta (60) anos, a Lei n. 10.741/03 (Estatuto do (doso), estabelece em seu artigo 17, parágrafo único e seus quatro incisos, quem deverá fazer isso por ele, em caso de incapacidade, ou seja, da sua impossibilidade de autodeterminarse em relação à sua pessoa, ao seu corpo. No entanto, no direito brasileiro, o Estatuto da Pessoa com Deficiência (Lei n. 13.146/15), em seu art. 84, estabelece que a pessoa que for incapaz, só o será no que disser respeito ao seu patrimônio. Por conseguinte, pelo citado Estatuto, o maior, ainda que sem condição de manifestar sua vontade de maneira hígida, posto ter alguma deficiência metal ou algum tipo de demência senil, deverá ter sua vontade preservada, sem necessidade de ser suprida pelo responsável legal, na hipótese de ele ter sido colocado sob curatela. Tal situação coloca essa pessoa em risco. Isto significa que sua dignidade não estará sendo respeitada, posto ela não ter condições de exercer aquilo que Bruno Souza Stancioli acertadamente denomina de capacidade de entendimento, que é o que culmina no exercício da autonomia existencial da pessoa. ${ }^{69}$

Ressalte-se que a Convenção de Direitos Humanos e Biomedicina, mais conhecida pela expressão Convenção de Oviedo, estabelece, em relação aos idosos, no art. $6^{\circ}$., 3, que, "[s]empre que, nos termos da lei, um maior careça, em virtude de deficiência mental, de doença ou por motivo similar, de capacidade para consentir numa intervenção, esta não poderá ser efectuada sem a autorização do seu representante, de uma autoridade ou de uma pessoa ou instância designada pela lei."70

Acrescente-se ainda, dois pontos relevantes, e que constam do Código de Ética Médica. O primeiro está no artigo 22 , que estabelece não poder o médico "[d]eixar de obter consentimento do paciente ou de seu representante legal após esclarecê-lo sobre o procedimento a ser realizado, salvo em caso de risco iminente de morte"71. O segundo encontrase no art. 24 do mesmo Código: "Deixar de garantir ao paciente o exercício do direito de decidir livremente sobre sua pessoa ou seu bem-estar, bem como exercer sua autoridade para limitá-

poderia fazer isso, se o assunto a ser solucionado pelo magistrado tiver a ver com a sua pessoa? Chega-se a esta conclusão, a partir do momento que o menor tem de ser ouvido até nos casos em que ele estiver para ser colocado em família substituta, como consta do $\S 2^{\circ}$., do art. 28 da Lei n. 8.069/90 (ECA). Até mesmo a Convenção de Direitos Humanos e Biomedicina, mais conhecida por Convenção de Oviedo, do ano de 1997, tem previsão neste sentido, em seu artigo $6^{\circ}$., 2: "Sempre que, nos termos da lei, um menor careça de capacidade para consentir numa intervenção, esta não poderá ser efectuada sem a autorização do seu representante, de uma autoridade ou de uma pessoa ou instância designada pela lei." E, continua o dispositivo em uma segunda parte: "A opinião do menor é tomada em consideração como um factor cada vez mais determinante, em função da sua idade e do seu grau de maturidade". (Grifos nossos) Disponível em: http://www.dhnet.org.br/direitos/sip/euro/principaisinstrumentos/16.htm. Acesso em: 4 Jul. 2020. Sobre o consentimento no caso do paciente estar sob poder familiar, v.: RODRIGUES, João Vaz. $O$ consentimento informado para o Acto Médico no Ordenamento Jurídico Português. (Elementos para o Estudo da Manifestação da Vontade do Paciente). Coimbra: Coimbra, 2001, p. 209 e s.

${ }^{69}$ Para aprofundar este tema, v. GOZZO, Débora; MONTEIRO, Juliano Ralo. O idoso com demência senil ou deficiente mental na relação jurídica médico-paciente. In: ROSENVALD, Nelson. BEZERRA DE MENEZES, Joyceane. DADALTO, Luciana. (Coord.). Responsabilidade Civil e Medicina. Indaiatuba: Foco, 2020, p. 97 e s.

70 Disponível em: http://www.dhnet.org.br/direitos/sip/euro/principaisinstrumentos/16.htm. Acesso em: 4 jul. 2020.

71 Disponível em: http://portal.cfm.org.br/images/PDF/cem2019.pdf. Acesso em: 3 Jul.2020. 
lo"72. Pelos dispositivos transcritos, pois, o Conselho Federal de Medicina ao mesmo tempo em que impõe aos médicos o dever de informar o paciente, determina o dever de respeitar a livre vontade, a autonomia, a autodeterminação dessa pessoa.

Aplicando-se tudo o que foi escrito neste e nos itens anteriores, e levando-se em conta a falta de evidência científica no emprego da Cloroquina e da Hidroxicloroquina, o consentimento informado e esclarecido, ainda mais em casos como a da Covid-19, que podem e têm levado muitos à morte, faz-se imprescindível. Se o paciente não tiver condições de exercer sua autonomia existencial, imperioso que seu representante ou assistente legal o faça. Os riscos aos quais ele será submetido, dentro dos conhecimentos científicos já disponiveis em relação ao tratamento dessa moléstia, têm de ser-lhe informados, de modo a que o paciente possa compreendê-los (capacidade de entendimento). Só assim ele terá preservada sua dignidade.

\section{SOBRE A (NÃO) RESPONSABILIZAÇÃO CIVIL DO MÉDICO NO USO DA CLOROQUINA E DA HIDROXOCLOROQUINA}

Da análise dos estudos apreciados nos itens acima e, em especial, dos pareceres técnicos de especialistas na área de infectologia há uma uniformidade que o emprego da Cloroquina e da Hidroxicloroquina para tratamento da Covid-19 está mais alinhado como uma "terapia de salvamento experimental"73.

De fato. Mesmo diante do conglomerado de pesquisas, pareceres e estudos não conclusivos sobre a eficiência do uso da Cloroquina e da Hidroxocloroquina será importante o médico prescritor obter respaldo do Comitê de Ética do Hospital assentado em termo de consentimento do paciente ou da família (paciente intubado, deficiente mental etc.) e decidir sobre a aplicação, ou não, do medicamento chancelado pelo Ministério da Saúde, em maio de 2020.

Nesse impasse, de perguntar-se: quando o médico decide, ou não, pelo uso do medicamento indicado pelo Protocolo do Ministério da Saúde? Será que os delineamentos tradicionais da responsabilidade civil podem conferir segurança jurídica aos profissionais da saúde em tempos de pandemia do Coronavírus? Como poderia ser traçado um planejamento jurídico e ético na atuação do médico destinado à sua própria proteção e daqueles que são por ele assistidos?

Mister atentar-se que, no Estado de Direito, a saúde dos cidadãos é de grande relevância, posto coincidir com a necessidade de serem adotadas políticas públicas adequadas para atender não só à demanda populacional, como também para solucionar os abusos e/ou

\footnotetext{
72 Disponível em: http://portal.cfm.org.br/images/PDF/cem2019.pdf. Acesso em: 3 Jul.2020.

${ }^{73}$ Disponível em: https://www.infectologia.org.br/admin/zcloud/125/2020/03/c9b8d4f743ac65349e051b8638 af7ee90d9a41f2f09a84f0ff83fc559fdf8b5f.pdf. Acesso em 16 Jun. 2020. A Lei 13.989, de 15 de abril de 2020 pode ser citada como flexibilização das exigências em relação à atuação do médico. A lei autorizou o exercício da telemedicina durante o período da pandemia, relativizando a essencialidade do contato presencial com os pacientes. É um exemplo da resposta do Direito à necessidade de adaptar a atuação do médico aos novos tempos.
} 
danos que possam advir por parte dos profissionais da saúde, tanto do poder público quanto do setor privado, em relação aos seus assistidos.

Por esta razão, para análise de cada caso, deve-se observar o implícito princípio da proteção, previsto nos artigos 196 e seguintes da Constituição. Na avaliação da conduta médica é importante que seja averiguado, se foi cumprido o dever de tutela do melhor interesse do paciente, como norteador da relação médico-paciente. Isso significa dizer que a boa-fé objetiva será o vértice para proteção jurídica das duas partes.

Em tal caso, como se pode perceber a boa-fé na relação médico-paciente? Potencialmente quando esse dever anexo é feito com informação clara, esclarecida, ostensiva, sem nuances, respeito, com equidade, com linguagem própria ao paciente e assim tenha como ele exercer, com autonomia ${ }^{74}$ ( $v$ item 3 , supra), uma decisão para o enfrentamento do mal acometido.

Note-se que numa visão intrínseca do paciente, reconhece-se que ele possa se sentir mais vulnerável frente ao médico. ${ }^{75}$ Isto porque, por vezes, ele se sente aquém do poder-saber deste profissional. Percebe-se que há uma assimetria no diálogo entre médico e paciente ${ }^{76}$. Assim é que, a despeito das informações claras e compreensíveis - transparentes - que ele possa receber do médico, por vezes ele não se sente em condições de influenciar não só sobre as propostas de tratamento, mas, também, sobre a forma da condução de sua trajetória clínica. Por isso é importante mencionar o art. 34 do Código de Ética Médica, que realça a proibição de "deixar de informar o paciente o diagnóstico, o prognóstico, os riscos e os objetivos do tratamento, salvo quando da comunicação direta possa lhe provocar dano, devendo, nesse caso, fazer a comunicação a seu representante legal." ${ }^{77}$

\footnotetext{
${ }^{74}$ Recomendação CFM n 01/2016 aborda sobre Consentimento Informado, e propõe, dentre outras condutas, que haja esclarecimento claro, com pertinência à circunstância específica, proporcionando uma possível decisão segura do paciente em autorizar a realização de procedimentos, estimulando a elaboração de termo escrito, com linguagem adequada à compreensão, em que pese não considerar ilícito ético a obtenção verbal. Disponível em: https://sistemas.cfm.org.br/normas/visualizar/recomendacoes/BR/2016/1>. Acesso em: 18 Jun. 2020. Cf. "O princípio da autonomia requer que os indivíduos capacitados de deliberarem sobre suas escolhas pessoais, devam ser tratados com respeito pela sua capacidade de decisão. As pessoas têm o direito de decidir sobre as questões relacionadas ao seu corpo e à sua vida. Quaisquer atos médicos devem ser autorizados pelo paciente". Princípios bioéticos. A Autonomia, NãoMaleficência, Beneficência, Justiça e Equidade. Disponível em: http://www.bioetica.org.br/?site Acao=Publicacoes\&acao=detalhes_capitulos\&cod_capitulo=53\&cod_publicacao=6. Acesso em: 2 jul. 2020.

75 Nas palavras de Cláudia Lima Marques e Bruno Miragem, "vulnerabilidade é mais um estado da pessoa, um estado inerente de risco ou um sinal de confrontação excessiva de interesses identicado no mercado, é uma situação permanente ou provisório, individual ou coletiva que fragiliza, enfraquece o sujeito de direitos, desequilibrando a relação. A vulnerabilidade não é, pois, o fundamento das regras de proteção do sujeito mais fraco, é apenas a 'explicação' destas regras ou da atuação do legislador, é a técnica para as aplicar bem, é a noção instrumental que guia e ilumina a aplicação destas normas protetivas e reequilibradoras, à procura do fundamento da Igualdade e da Justiça equitativa". MARQUES, Cláudia Lima; MIRAGEM, Bruno. O novo Direito Privado e a Proteção dos Vulneráveis. São Paulo: Revista dos Tribunais, 2012, p. 117.

76 OLIVEIRA, Camila Vasconcelos de. Judicialização da medicina no Brasil: uma análise crítico-propositiva de um problema persistente sob a ótica da Bioética de Intervenção, Brasília, 2017. 155f. Tese (Doutorado) - Universidade de Brasília/Programa de Pós-Graduação em Bioética, Brasília, 2017, p. 79.

77 Disponível em: http://portal.cfm.org.br/images/PDF/cem2019.pdf. Acesso em: 3 Jul.2020.
} 
A estruturação do consentimento do paciente, além de seu viés jurídico, está intrinsecamente ligada à Bioética ${ }^{78}$. Isto porque, tratando da ética aplicada ${ }^{79}$ ela traz soluções aos problemas, ou seja, resolutividade ${ }^{80}$.

$\mathrm{Na}$ área da saúde, como visto acima no item anterior, o consentimento deve ser analisado no contexto da autonomia do paciente, mas também conjugado com a informação esclarecida. Isso quer dizer que o profissional da saúde deve informar ao paciente, ou ao seu responsável, todas as nuances do procedimento a ser realizado. Ou seja, o médico deve ter a percepção de qual vocabulário é passível de entendimento a aquele paciente (condições sócioculturais ${ }^{81}$ e conduzir com sapiência o quadro clínico explicando, ao paciente, inúmeras vezes, se for o caso ${ }^{82}$. Sobreleva, dessa maneira, a dignidade humana do doente, conforme ensina Daisy Gogliano:

Toda e qualquer terapêutica médica tem por fundamento e por pressuposto o respeito à dignidade humana, na tutela de direitos privados da personalidade $e$ na relação médico-paciente, em que sobreleva o direito ao respeito da vontade do paciente sobre o tratamento; o direito do doente ou enfermo à dignidade e à integridade (físico-psíquica); o direito à informação que se deve fundar no consentimento esclarecido; o direito à cura apropriada e adequada; o direito de não sofrer inutilmente, na proporcionalidade dos meios a serem empregados, na diferenciação que se impõe entre terapêutica ineficaz e terapêutica fútil, isto é, na utilização de uma terapia racional e vantajosa, que não conduza a uma terapia violenta e indigna. ${ }^{83}$

78 "[...] A bioética é [...]a ética aplicada à vida, um novo domínio da reflexão e da prática, que toma como seu objetivo específico as questões humanas na sua dimensão ética, tal como se formulam no âmbito da prática clínica ou da investigação científica, e como método próprio a aplicação de sistemas éticos já estabelecidos ou de teorias a estruturar". Princípios bioéticos. A Autonomia, Não-Maleficência, Beneficência, Justiça e Equidade. Disponível em: http://www.bioetica.org.br/?siteAcao=Publicacoes\& acao $=$ detalhes_capitulos\&cod_capitulo=53\&cod_publicacao=6. Acesso em: 2 Jul. 2020.

${ }^{79}$ A ética aplicada é o ramo da ética preocupada com a análise de questões morais particulares na vida privada e pública. "A ética, como expressão única do pensamento correto conduz à ideia da universalidade moral, ou ainda, à forma ideal universal do comportamento humano, expressa em princípios válidos para todo pensamento normal e sadio". FARIAS, Adriana. Legislação e Ética Profissional. Disponível em: http://www.crc-ce.org.br/crcnovo/download/apost_eticacrc.pdf>. Acesso em: 2 Jul. 2020.

80 OLIVEIRA, Camila Vasconcelos de. 16 de jun. de 2020. Autonomia do Paciente, Consentimento e Responsabilidade Civil. Webinar Especial IBERC. Disponível em: https://www.youtube.com/ watch?v=_MH2pF7Yt7g. Acesso em: 21 jun. 2020.

81 "O modelo de análise bioética comumente utilizado e de grande aplicação na prática clínica na maioria dos países é o 'principalista', introduzido por Beauchamp e Childress, em 1989. Esses autores propõem quatro princípios bioéticos fundamentais: autonomia, beneficência, não-maleficência e justiça". Princípios bioéticos. op.cit. Disponível em: http://www.bioetica.org.br/?siteAcao=Publicacoes\&acao=detalhes_capi tulos\&cod_capitulo=53\&cod_publicacao=6. Acesso em 02. jul. 2020.

82 "O médico deve manter uma comunicação adequada com os pacientes e suas famílias. Se ele agir desta forma, em vez de medicina defensiva, se praticará "medicina assertiva" e, ser assertivo implica ter atitudes de oferecer segurança, de forma respeitosa e boa comunicação. A prática da medicina assertiva favorece a confiança do paciente e facilita a boa relação médico-paciente. [...] Ainda que o profissional tenha plena percepção da assertividade de sua prática, há outros fatores dificulta assertividade dos médicos brasileiros, tais como: cansaço físico por trabalho noturno e finais de semana, tem que contornar problemas sociais, condições de trabalho precárias, paciente que não tem condição de adquirir medicação, dificuldade para internar, falta de vagas, dificuldade de investigação com exames complementares, caros e pouco disponíveis quando feitos pelo SUS". OLIVEIRA, Camila Vasconcelos de. Judicialização da medicina no Brasil: uma análise crítico-propositiva de um problema persistente sob a ótica da Bioética de Intervenção. 2017. 155f. Tese (doutorado) - Universidade de Brasília/Programa de Pós-Graduação em Bioética, Brasília, 2017, p. 55 e 56.

83 GOGLIANO, Daisy. Pacientes terminais - morte encefálica. In: Revista Bioética, Brasília, v. 1, n. 2, p. 145156, 1993, apud Princípios bioéticos. A Autonomia, Não-Maleficência, Beneficência, Justiça e Equidade. 
Será, enfim, a vontade expressada pelo paciente no consentimento, que é um processo (pro cedere), no qual se percorrem fases e, ao final, reduz-se a termo no prontuário (ou outro documento) do paciente ${ }^{84}$, que deverá ser respeitada.

A comunicação entre médico e paciente é, portanto, crucial. Sendo ela demonstrada em juízo, poderá dar suporte à solução de demandas médicas e/ou hospitalares. Acredita-se que as circunstâncias e variáveis do caso concreto deverão nortear como se dará a proteção da vítima do dano, e a medida da responsabilidade civil do médico, inclusive, se houve perda de uma chance por conduta médica que deixa de prescrever (ou não) medicamento, como a Hidroxicloroquina, por exemplo.

Fundamental é perquirir, se houve ou não o efetivo cumprimento do dever de informação.

Desta forma, a imputação de responsabilidade ao médico pela decisão tomada pelo uso (ou não) da Cloroquina ou da Hidroxicloroquina deve ser apreciada em conjunto com o que há na realidade desta pandemia. Ou seja: deve-se considerar problemas como a de falta de servidores, equipamentos, leitos, respiradores, análise de todas as recomendações oficiais emitidas pelo Ministério da Saúde e órgãos médicos, dentre outras situações para cada caso.

Naturalmente, deverá haver pesos e contrapesos na análise da conduta do médico, equipe e/ou hospital, nas diligências realizadas em pacientes com Covid-19 (e também nos demais pacientes). Todavia, isso não quer dizer que seja possível haver uma crença absoluta numa flexibilização da conduta médica mesmo em situações extraordinárias para enfrentamento do Coronavírus, mas, sim, um olhar depurado e racional para as evidências do caso concreto, e que fez o profissional da saúde, naquele instante, tomar determinadas condutas, incluindo a prescrição (ou não) da Cloroquina e da Hidroxocloqrina para salvar ou melhorar a saúde do paciente.

O médico, juntamente com sua equipe, pode concluir que diante das recomendações feitas pelos protocolos dos órgãos oficiais para o uso de medicamentos off label, ou com alguma possibilidade de curar o paciente ou, ainda, na iminência da morte deste, resolver pelo uso de medicamento sem testes conclusivos para o tratamento da Covid-19.

Foi por conta desse cenário, que Conselho Federal de Medicina, no Parecer nº 04/2020 concluiu: "A única estratégia reconhecida até o momento para prevenir a infecção é evitar a exposição ao vírus"; e, conclui na letra "e" do parecer que: "Diante da excepcionalidade da situação e durante o período declarado da pandemia, não cometerá infração ética o médico que

Disponível em: http://www.bioetica.org.br/?siteAcao=Publicacoes\&acao=detalhes_capitulos\&cod_capitulo $=53 \&$ cod_publicacao=6. Acesso em: 2 jul. 2020.

$84 \mathrm{O}$ consentimento pode ser oral e tácito, também. Pode ocorrer que o paciente não tenha condições psíquicas de tomar decisão e, neste caso, o médico reportará ao seu representante legal, também pode ocorrer que o paciente está em iminência de morte e o médico decide. 
utilizar a cloroquina ou hidroxicloroquina, nos termos acima expostos, em pacientes portadores da Covid $-19 . " 85$

Atentando-se para esta hipótese excepcional do atual estado de pandemia, fortemente se é estimulado a defender o afastamento da responsabilidade civil médica, a qual permanece, para todos os efeitos, sendo examinada subjetivamente, por algumas condutas tomadas para o enfrentamento da Covid-19.

Mas, efetivamente, como saber qual(is) conduta(s) médica(s) no enfrentamento da pandemia poderiam constituir-se em excludente de responsabilidade?

No anseio de dissipar essas possíveis atribuições de responsabilidades nas ações dos profissionais da saúde, o Governo Federal emitiu Medida Provisória n 966/2086 que restringiu a responsabilização dos agentes públicos durante a epidemia de Covid-19.

Pela referida Medida Provisória, os agentes públicos somente poderão ser responsabilizados nas esferas civil e administrativa, se agirem, ou se omitirem com dolo ou erro grosseiro, a prática de atos relacionados com as medidas de enfrentamento à pandemia e aos efeitos econômicos e sociais dela decorrentes.

Diante do teor da Medida Provisória n. 966/2020 e, vista a notória inconstitucionalidade com relação aos princípios da razoabilidade e proporcionalidade ${ }^{87}$, foram ajuizadas ações pelas quais se sustentaram que os critérios da citada Medida implicariam anistia ou, salvo-conduto a toda e qualquer atuação estatal desprovida de dolo ou erro grosseiro ${ }^{88}$.

As liminares apreciadas pelo Relator Luís Roberto Barroso ${ }^{89}$ foram parcialmente deferidas, tendo sido dada interpretação conforme a Constituição, para estabelecer que:

1. Configura erro grosseiro o ato administrativo que ensejar violação ao direito à vida, à saúde ou ao meio ambiente equilibrado por inobservância: (i) de normas e critérios científicos e técnicos; (ii) dos princípios constitucionais da precaução e da prevenção.

2. A autoridade a quem compete decidir deve exigir que as opiniões técnicas em que baseará sua decisão tratem expressamente: (i) das normas e critérios científicos e técnicos aplicáveis à matéria, tal como estabelecidos por organizações internacional e nacionalmente reconhecidas; e (ii) da observância dos princípios constitucionais da precaução e da prevenção, sob pena de se tornarem corresponsáveis por eventuais violações a direitos.

\footnotetext{
${ }^{85}$ Disponível em: https://sistemas.cfm.org.br/normas/visualizar/pareceres/BR/2020/4. Acesso em: 30 jun. 2020.

86 Disponível em: http://www.planalto.gov.br/ccivil_03/_ato2019-2022/2020/mpv/mpv966.htm. Acesso em: 17 jun. 2020.

87 "Vê-se, pois, que o critério da razoabilidade exprime uma tentativa de determinação do critério ou critérios que incidirão no caso concreto [...] compreende-se o denominado princípio da proporcionalidade, a Grundstaz der VerhältnismäBigkeit, também chamado de mandamento da proibição de excesso (UbermaBverbot)como um guia à atividade interpretativa, que indiscutivelmente apresenta grande liberdade de atuação, tendo em vista os fins a serem atingidos, e a exigibilidade da escolha destes". BASTOS, Celso Ribeiro. Hermenêutica e Interpretação Constitucional. 2. ed. rev.e ampl., São Paulo: Celso Bastos, 1999, p. 185.

88 Processos: ADIns 6.421, 6.422, 6.424, 6.425, 6.427, 6.248 e 6.431 .

89 Voto Disponível em: https://www.migalhas.com.br/arquivos/2020/5/C8CE49A83E45F6_Irb.pdf. Acesso em: 16 jun. 2020.
} 
O entendimento de Luís Roberto Barroso delimitou, especialmente, que agentes públicos que pratiquem atos administrativos que violem o direito à vida, à saúde, ou ao meio ambiente, por descumprimento de normas e critérios científicos e técnicos, cometem erro grosseiro e, portanto, estão sujeitos a sanções legais.

E nesse sentido, por maioria, os ministros seguiram o entendimento do Relator. Ao final, Alexandre de Moraes propôs a exclusão do advérbio somente, bem como a suspensão integral do inciso II do dispositivo que segue ${ }^{90}$ :

Art. $1^{\circ}$ Os agentes públicos somente poderão ser responsabilizados nas esferas civil e administrativa se agirem ou se omitirem com dolo ou erro grosseiro pela prática de atos relacionados, direta ou indiretamente, com as medidas de:

I - enfrentamento da emergência de saúde pública decorrente da pandemia da covid-19; e

II - combate aos efeitos econômicos e sociais decorrentes da pandemia da covid-19.

Para Alexandre de Moraes, este trecho é muito amplo, e acaba atribuindo excludente de ilicitude. Ele delimitou quatro vetores constitucionais obrigatórios em relação à responsabilização dos agentes públicos: "a) fiscalização dos Tribunais de contas; b) diferenciação entre responsabilidades civil e administrativa x improbidade administrativa; c) direito de regresso em caso de dolo ou culpa e d) prazos de prescrição para ilícitos praticados por qualquer agente". 91

Desta forma, o julgamento das ações diretas de inconstitucionalidade que questionaram a Medida Provisória n. 966/20 pelo Supremo Tribunal Federal, sedimentou o entendimento de que ignorar diretrizes científicas constitui erro grosseiro, o que abre a possibilidade para questionamento judicial e posterior condenação.

Com efeito, a atuação do médico é considerada lícita quando segue as normas de segurança e eficácia constatadas pelas evidências científicas. É isso que irá repercutir na responsabilidade civil do médico.

Assim, observe-se que a prescrição off label não é proibida por lei. Esse medicamento, só por ser off label, pode ser usado de forma diferente. Porém, o médico que prescrevê-lo deve ter em vista alguns fatores que contribuem para esta prescrição, quais sejam: se o caso é extremo; se houve esclarecimento que não existem outras terapias testadas para Covid-19; se atentou ao melhor interesse do paciente; e, em especial, se houve um consentimento informado e esclarecido ${ }^{92}$ do paciente, o qual tenha sido construído em conjunto com o médico, e que

90 Disponível em: https://www.migalhas.com.br/quentes/327455/stf-define-o-que-e-erro-grosseiro-pararesponsabilizar-agentes-publicos. Acesso em: 14 jun. 2020.

91 Disponível em: https://www.migalhas.com.br/quentes/327455/stf-define-o-que-e-erro-grosseiro-pararesponsabilizar-agentes-publicos. Acesso em: 14 de jun. de 2020.

92 Resolução CFM n 2.217/18, art. 41, parag. Único: "Nos casos de doença incurável e terminal, deve o médico oferecer todos os cuidados paliativos disponíveis sem empreender ações diagnósticas ou terapêuticas inúteis ou obstinadas, levando sempre em consideração a vontade expressa do paciente ou na sua impossibilidade, a de seu representante legal." 
nesse panorama traçado, possa contribuir com o afastamento da responsabilidade civil do médico.

Acrescente-se que, para que o médico responda civilmente pelo uso de medicamento off label dever-se-á analisar, concomitantemente, se houve a ocorrência dos pressupostos legais (ação, culpa, nexo causal e dano), se foi cumprido o dever de informar o paciente e obter o consentimento informado e esclarecido com respeito a todas as fases.

Tudo isso é de caráter relevante para a decisão livre do paciente. O zelo do médico que respeita todas as fases do consentimento, deixando o paciente exercitar sua autonomia existencial, legitima sua conduta adotada para cada caso concreto.

Só a confiança recíproca na relação médico-paciente e a simetria dessa relação é que pode otimizar o tratamento do paciente com Covid-19, evitando tanto interpretações equivocadas sobre possíveis resultados desfavoráveis, quanto a judicialização ${ }^{93}$.

Apesar do Judiciário poder se socorrer de perícia técnica para averiguar sobre o procedimento médico, tais como, se a conduta por parte do profissional da saúde foi diligente e prudente, as questões relacionadas à ciência médica são múltiplas e complexas e, ainda, sujeitas a visões díspares de cientistas médicos e, que não se comunicam.

Não é simples solucionar as demandas judiciais que tratam de responsabilidade civil médica (como também outras relacionadas à área da tecnologia e inteligência artificial), seja por conta da necessidade de se investigar muito além do âmbito da culpa médica na conduta do procedimento clínico/terapêutico/hospitalar, mas também com relação à identificação de eventual manifestação da autonomia do paciente na tomada de decisão. Da análise desta, pode-se isentar (ou não) o profissional da saúde do dano ocorrido.

Por estas e outras razões acredita-se ${ }^{94}$ de lege ferenda que a criação de Varas Especializadas em Responsabilidade Civil (não Juízo de Exceção para Covid-19) - tais como as "recentes" varas de recuperação judicial e violência doméstica - exerceriam e fortaleceriam os estudos avançados e contemporâneo da responsabilidade civil em geral, além de conferir maior efetividade e percepção social ${ }^{95}$.

93 “[...] quanto à judicialização da medicina, devem ser considerados dois contextos concomitantes [...]. O primeiro, em que há uma busca assertiva ao Poder Judiciário para a resolução de litígios entre médicos e pacientes, como reflexo de um processo de empoderamento dos pacientes que, na medida em que se tornam conhecedores de seus direitos, fazem uso do direito constitucional de ação, provocando o judiciário na tentativa de resguardo de seus interesses. Neste segundo sentido, pode-se observar a conformação de demandas judiciais que poderiam ser evitadas a partir da prévia simetralização do discurso entre médicos e pacientes em uma tentativa de diálogo, o que, possivelmente, propiciaria maior compreensão de circunstâncias próprias à medicina, afastadas de qualquer possibilidade de cometimento de erro médico, mas que podem vir a ser judicializadas. E o segundo, em que há uma busca excessiva ao Poder Judiciário, em uma tentativa de ocupá-lo do encontro de soluções de problemas presentes na relação entre médicos e pacientes a partir da assimetria de poder/saber e as dificuldades no exercício dos discursos tendo em vista falhas no diálogo (101), e que poderiam ser enfrentadas de outro modo [...]". OLIVEIRA, Camila Vasconcelos de. Judicialização da medicina no Brasil: uma análise crítico-propositiva de um problema persistente sob a ótica da Bioética de Intervenção. 2017. 155f. Tese (doutorado) - Universidade de Brasília/Programa de Pós-Graduação em Bioética, Brasília, 2017, p. 53.

${ }_{94}$ Proposta de lege ferenda da coautora Raquel Helena Valési.

$95 \mathrm{Em}$ raciocínio semelhante, mas ligado à responsabilidade civil médica, Camila Vasconcelos ensina que "[...] enseja a valorização da imersão do âmbito judicial, entretanto, mais especificamente anterior: propõe a 
As contendas, nestas Varas Especializadas, relacionadas à responsabilidade civil médica, área de tecnologia, inteligência artificial, dentre outros infinitos assuntos, teriam participação de operadores do direito (juízes, promotores, advogados, peritos, mediadores, outros), cuja formação ou, acentuada dedicação nesta área (re)construiriam proposições jurídicas nestes vários temas sobre responsabilidade civil, além de uma jurisprudência mais sólida sobre a reparação (ou não) do dano e sua quantificação, tudo com base em reflexões jurídicas/científicas bem aprofundadas e delineadas em cada caso concreto. Acredita-se.

Por fim, será necessário um olhar cauteloso do jurista, pois os pressupostos tradicionais da responsabilidade civil podem não ser suficientes para solucionar demandas judiciais relacionadas à pandemia do Coronavírus.

\section{CONCLUSÃO}

Diante do cenário temerário que estamos vivendo, imprescindível que as decisões dos profissionais da saúde sejam informadas por robustas evidências científicas, isto para que as ações de hoje possam ter maior probabilidade de conferir mais benefícios do que riscos à população.

Qualquer recomendação sobre o uso de medicamentos para o tratamento da Covid-19 deve ser pautada em estudos técnicos seguros, metodologicamente estruturado, randomizado e cego, como afirmado no texto.

Além disso, o cumprimento do dever de informar o paciente, obtendo dele consentimento esclarecido com respeito a todas as fases dessa coleta, terá caráter decisivo na avaliação da conduta adotada pelo médico e na sua eventual responsabilização.

Por derradeiro, o médico responderá civilmente pelo uso de medicamento off label e sem comprovação de eficácia para Covid-19 se, concomitantemente, tiver havido a ocorrência dos pressupostos legais (ação, culpa, nexo causal e dano), não tendo havido o cumprimento do dever de informar o paciente, a fim de obter dele o consentimento esclarecido de forma clara, precisa e, em linguagem adequada, mostrando os efeitos da aplicação da Cloroquina e da Hidroxicloroquina.

Destaca-se, por fim, que a confiança recíproca na relação médico-paciente e a simetria dessa relação é que pode otimizar o tratamento do paciente com Covid-19, evitando-se não só interpretações equivocadas sobre possíveis resultados desfavoráveis, bem como a judicialização do caso.

criação de Câmaras de Mediação de Conflitos na Assistência em Saúde. Esta perspectiva extrajudicial, em que pese não estar ainda sob a égide direta do poder judiciário, é uma manifestação de possível resolutividade autocompositiva de problemas que, por consequência, poderá ter seu acordo executado no judiciário". OLIVEIRA, Camila Vasconcelos de. Judicialização da medicina no Brasil: uma análise críticopropositiva de um problema persistente sob a ótica da Bioética de Intervenção. 2017. 155f. Tese (doutorado) - Universidade de Brasília/Programa de Pós-Graduação em Bioética, Brasília, 2017, p. 138. 


\section{REFERÊNCIAS}

ABEJA, Laura Gómez. El derecho a rechazar el tratamiento médico: análisis de los antecedentes desde una perspectiva constitucional. Valencia: Tirant, 2014.

AZEVEDO. Antonio Junqueira de. (Parecer) Natureza jurídica do contrato de consórcio (sinalagma indireto). Onerosidade excessiva e em contrato de consórcio. Resolução parcial do contrato. In: AZEVEDO, Antonio Junqueira de. Novos Estudos e Pareceres de Direito Privado. São Paulo: Saraiva, 2009.

BASTOS, Celso Ribeiro. Hermenêutica e Interpretação Constitucional. 2. ed. rev.e ampl. São Paulo: Celso Bastos Editor, 1999.

BEAUCHAMP, Tom L.; CHILDRESS, James F. Princípios de Ética Biomédica. 2. ed. Tradução de Luciana Pudenzi. São Paulo: Loyola, 2011.

BERGAMO, Mônica. Maior Estudo do país vê hidroxocloroquina ineficaz contra Covid. Folha de S. Paulo, São Paulo, ano 100, n. 33.250, 24 de jul. de 2020.

BMJ. Chloroquine and hydroxychloroquine in Covid-19. BMJ, 8 abr. 2020. Disponível em: https://doi.org/10.1136/bmj.m1432. Acesso em: 17 jun. 2020.

BRAGA NETTO, Felipe Peixoto; FARIAS, Cristiano Chaves de; Rosenvald, Nelson. Curso de Direito Civil. 3. ed. rev. atual. Salvador: Juspodivm, 2016, v. 3.

BARBOSA, Carla; MATOS, Mafalda Francisco. Prescrição off-label, direito à informação, consentimento informado e processo clínico eletrônico no direito português. Cadernos IberoAmericanos de Direito Sanitário. Brasília, v. 5, n. 3, p. 157-179, 2016.

CENTRO DE BIOÉTICA DO CREMESP. Princípios Bioéticos. A autonomia, não-maleficência, beneficência, justiça e equidade. Disponível em: http://www.bioetica.org.br/?siteAcao= Publicacoes\&acao=detalhes_capitulos\&cod_capitulo=53\&cod_publicacao=6. Acesso em: 2 jul. 2020.

DADALTO, Luciana; SOARES, Flaviana Rampazzo. Responsabilidade médica e prescrição offlabel de medicamentos no tratamento da Covid-19. Revista IBERC, Belo Horizonte, v. 3, n. 2, Ahead of Print, maio./ago. 2020. Disponível em: https://doi.org/10.37963/iberc.v3i2.112. Acesso em: 27 jun. 2020.

DINIZ, Debora. GUILHEM. Dirce. O que é bioética? São Paulo: Brasiliense, 2007.

FARFAN, Tainá. Governo muda protocolo e autoriza hidroxicloroquina para casos leves de Covid-19. CNN Brasil. 20 maio 2020. Disponível em: https://www.cnnbrasil.com.br/saude/ 2020/05/20/governo-muda-protocolo-e-autoriza-hidroxicloroquina-para-casos-leves-de-covid-19. Acesso em 18 jun. 2020.

FERREIRA, Lilian de Abreu, et al. A alta prevalência de prescrições de medicamentos off-label e não licenciados em unidade de terapia intensiva pediátrica brasileira. Revista da Associação Médica Brasileira. São Paulo, v. 58, p. 82-87, 2012.

MIGALHAS. STF define o que é "erro grosseiro" para responsabilizar agentes públicos. 21 de maio de 2020. Disponível em: https://www.migalhas.com.br/quentes/327455/stf-define-o-que-eerro-grosseiro-para-responsabilizar-agentes-publicos. Acesso em: 21 jun. 2020.

GOZZO, Débora. Transparência, informação e a relação médico-paciente. In: GOZZO, Débora (Coord.). Informação e Direitos Fundamentais: a eficácia horizontal das normas constitucionais. São Paulo: Saraiva, 2012. 
GOZZO, Débora; MONTEIRO, Juliano Ralo. O idoso com demência senil ou deficiente mental na relação jurídica médico-paciente. In: ROSENVALD, Nelson. BEZERRA DE MENEZES, Joyceane. DADALTO, Luciana. (Coord.). Responsabilidade Civil e Medicina. Indaiatuba: Foco, 2020.

GOZZO, Débora; MONTEIRO, Juliano Ralo. A concretização da autonomia existencial e a Lei $\mathrm{n}$. 13.146/15: apontamentos sobre o casamento da pessoa com deficiência. Civilistica.com, Rio de Janeiro, a. 8, n. 1, 2019. Disponível em: http://civilistica.com/wp-content/uploads/2019/04/Gozzoe-Monteiro-civilistica.com-a.8.n.1.2019.pdf. Acesso em: 30 jun. 2020.

HERRMANN, Ana Paula. Cloroquina contra o Coronavírus: existe evidência por trás da esperança. Disponível em: https://www.ufrgs.br/coronavirus/base/artigo-cloroquina-contra-ocoronavirus-existe-evidencia-por-tras-da-esperanca/. Acesso em: 17 jun. 2020.

PACHECO, Rafael Leite; RIEIRA, Rachel. Hidroxicloroquina para Infecção por Covid-19. Conselho Nacional de Justiça, 20 mar. 2020. Disponível em: https://www.cnj.jus.br/enatjus/arquivo-download.php?hash=3662fc98904c4e52296b31c6d21c5ebabfef6cb9. Acesso em: 10 jun. 2020.

MARASCIULO, Marília. Os riscos da cloroquina e da hidroxicloroquina no tratamento da Covid19. Galileu, maio 2020. Disponível em: https://revistagalileu.globo.com/Ciencia/Saude/noticia/ 2020/05/os-riscos-da-cloroquina-e-da-hidroxicloroquina-no-tratamento-da-covid-19.html. Acesso em: 20 jun. 2020.

MADERO, Carlos. Em nova diretriz, sociedades médicas do país recomendam não usar cloroquina. UOL, 19 maio 2020. Disponível em: https://noticias.uol.com.br/saude/ultimasnoticias/redacao/2020/05/19/em-nova-diretriz-sociedades-medicas-do-pais-recomendam-naousar-cloroquina.htm. Acesso em: 18 Jun. 2020.

MARQUES, Cláudia Lima; MIRAGEM, Bruno. O novo Direito Privado e a Proteção dos Vulneráveis. São Paulo: Revista dos Tribunais, 2012.

MARQUES FILHO, José. Relação Médico-Paciente - Autonomia ou Paternalismo? In: PEREIRA FILHO, Antônio. MARQUES FILHO, José. (Coords.). Bioética: Dilemas e Diálogos Contemporâneos. São Paulo: Cremesp, 2018.

MARTíNEZ-SILVEIRA. Martha Silvia. Revisões sistemáticas como fonte de evidências científicas em Saúde. 2015. 185f. Tese (Doutorado) - Instituto de Comunicação e Informação Científica e Tecnológica em Saúde. Pós-Graduação em Informação e Comunicação em Saúde, Rio de Janeiro, 2015.

NOGUEIRA, Roberto Henrique Porto. Responsabilidade Civil do Médico na Prescrição off label de medicamentos para Covid-19. 21 de abr. de 2020. Webinar Especial IBERC: "Coronavírus e Responsabilidade Civil". Disponível em: https://www.youtube.com/watch?v=TWAj8TZn8t0\&t= 17202s. Acesso em: 21 abr. 2020.

OLIVEIRA, Camila Vasconcelos de. Judicialização da medicina no Brasil: uma análise críticopropositiva de um problema persistente sob a ótica da Bioética de Intervenção. Brasília, 2017. 155f. Tese (doutorado) - Universidade de Brasília/Programa de Pós-Graduação em Bioética, Brasília, 2017.

OLIVEIRA, Camila Vasconcelos de. Autonomia do Paciente, Consentimento e Responsabilidade Civil. 16 de jun. de 2020. Webinar Especial IBERC. Disponível em: https://www.youtube.com/watch?v=_MH2pF7Yt7g. Acesso em: 21 jun. 2020.

PACHECO, Rafael Leite; RIEIRA, Rachel. Hidroxicloroquina para Infecção por Covid-19. 20 de mar. de 2020. Disponivel em: https://www.cnj.jus.br/e-natjus/arquivo-download.php?hash= 3662fc98904c4e52296b31c6d21c5ebabfef6cb9. Acesso em: 10 jun. 2020. 
PORTAL PEBMED. OMS suspende o uso da cloroquina e hidroxicloroquina em testes contra a Covid-19. Disponível em: https://pebmed.com.br/oms-suspende-o-uso-da-cloroquina-ehidroxicloroquina-em-testes-contra-a-covid-19/. Acesso em: 1 jul. 2020.

RAPOSO, Vera Lúcia. Da proteção dos consumidores-pacientes na prescrição off-label. Revista de Direito do Consumidor. São Paulo: Revista dos Tribunais, v. 110, p. 163-186, 2017.

RODRIGUES, João Vaz. O consentimento informado para o Acto Médico no Ordenamento Jurídico Português. (Elementos para o Estudo da Manifestação da Vontade do Paciente). Coimbra: Coimbra, 2001.

ROSENVALD, Nelson. BRAGA NETTO, Felipe. Código Civil Comentado. Salvador: Juspodivm, 2020.

STANCIOLI, Brunello Souza. Relação Jurídica Médico-Paciente. Belo Horizonte: Del Rey, 2004.

TERESINA, Bárbara Rodrigues. Ministério da Saúde libera cloroquina para todos pacientes com covid-19. GP1, 20 maio 2020. Disponível em: https://www.gp1.com.br/noticias/ministerio-dasaude-libera-cloroquina-para-todos-pacientes-com-covid-19-478237.html. Acesso em: 15 jun. 2020.

VENAGLIA, Guilherme. Hidroxicloroquina: o que é o remédio e por que ele divide médicos e políticos. Disponível em: http://portal.anvisa.gov.br/documents/219201/4340788/Nota+Técnica+ sobre+Cloroquina+e+Hidroxicloroquina.pdf/659d0105-60cf-4cab-b80a-fa0e29e2e799. Acesso em: 13 jun. de 2020.

WATANABE, Phillippe. The Lancet faz retratação de estudo que apontava maior risco de morte associado à hidroxicloroquina. Folha de S. Paulo, jun. 2020. Disponível em: https://www1. folha.uol.com.br/equilibrioesaude/2020/06/the-lancet-retrata-estudo-que-apontava-maior-risco-de -morte-associado-a-hidroxicloroquina.shtml. Acesso em: 1 jul. 2020.

Recebido: 24.06 .2020

Aprovado: 30.07 .2020

Como citar: VALESI, Raquel; GOZZO, Débora. Medicação aplicável à Covid-19, consentimento do paciente e responsabilidade civil do médico. Revista IBERC, Belo Horizonte, v. 3, n. 2, p. 241-267, maio/ago. 2020.

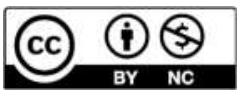

